\title{
Thermo-economic and sensitivity analysis of a central tower hybrid Brayton solar power plant
}

\author{
R.P. Merchán, M.J. Santos, J. García-Ferrero, A. Medina *, A. Calvo Hernández \\ Department of Applied Physics and IUFFYM, University of Salamanca, Salamanca, Spain
}

\section{A R T I C L E I N F O}

\section{Keywords:}

Thermo-solar hybrid power plants

Overall plant model

Thermo-economic analysis

Sensitivity of levelized cost of electricity

Subsystems integration

\begin{abstract}
A B S T R A C T
A hybrid central tower thermo-solar plant working with a gas turbine is simulated by means of an in-house developed model and software. The model considers the integration of all plant subsystems. The calculation of the heliostat solar field efficiency includes the main losses factors as blocking, shadowing, attenuation, interception, and cosine effect. The simulation considers a Brayton cycle for the power unit with irreversibilities in the compressor and turbine, and pressure drops in the heat absorption and extraction processes. A combustion chamber burning natural gas ensures an approximately constant power output. The model is flexible and precise. At the same time it is fast enough to perform sensitivity studies on the efficiency of any subsystem and the overall plant. Thus, it allows for performing a thermo-economic analysis of the plant checking the influence of the main plant design parameters. The focal objective is to analyze the importance on the levelized cost of electricity (LCoE) of the key plant design parameters. The direct influence of parameters from the heliostat field and receiver (as tower height, distance to the first row of heliostats, heliostats size, receiver size and heat losses, etc.) on final LCoE is surveyed. Similarly, parameters from the turbine as pressure ratio, turbine inlet temperature, influence of recuperation and others, are also analyzed. The dimensions of the plant are taken from SOLUGAS prototype near Seville, Spain, although another location with quite different solar conditions in Spain is also considered. LCoE values predicted are about 158 USD/MWh. The analysis concludes that among several parameters surveyed, two of them are key in LCoE predicted values: turbine inlet temperature and solar receiver aperture size.
\end{abstract}

\section{Introduction}

Thermo-solar power plants constitute, among renewable energies, one of the best alternatives to lead the global energy transition from carbonized to decarbonized energy sources $[1,2]$. Solar central tower systems stand out because of their promising high efficiencies and concentration ratios. In these systems, a heliostat field reflects and concentrates the solar radiation onto a solar receiver, located at the top of a central tower. Nowadays, most commercial projects employ a Rankine cycle in order to transform the concentrated solar heat into electricity [3]. Nevertheless, Brayton cycles can make use of air or other gas instead of water to move a turbine. Therefore, they seem interesting in areas with good insolation ratios that almost always bring about scarce hydric resources [4]. These plants are flexible to operate because thermal energy storage $[5,6]$ or hybridization can be implemented, reducing the undesirable impacts of solar energy fluctuations. A recent review on this point is due to Achkari and El Fadar [7].

In the research literature there are quite a lot works on central tower thermosolar plants but many of them are specialized in any of the subsystems. There are many accurate softwares to estimate and optimize solar field efficiencies either from theoretical assumptions or from MonteCarlo simulations as Campo Code [8], HFLCAL [9,10], SolTrace [11], and Tonatiuth [12]. A recent compilation and comparison among those models is due to Jafrancesco et al. [13]. Solar receivers technology, specially at the high temperatures required by Brayton cycles, is an open research field, both from the experimental viewpoint $[14,15]$ or from computational fluid dynamics or materials perspectives [16]. There are also different tools to predict the performance of the power units producing the electricity from the thermosolar input as TRNSYS [17], Thermoflex [18], EBSILON Professional [19], EES [20], etc., that have been used by many authors.

Nevertheless, our approach is different: to build a precise but not too intricate model for the whole plant, controlling at any moment the

\footnotetext{
* Corresponding author.

E-mail addresses: rpmerchan@usal.es (R.P. Merchán), smjesus@usal.es (M.J. Santos), jgferrero@usal.es (J. García-Ferrero), amd385@usal.es (A. Medina), anca@ usal.es (A.C. Hernández).
} 


\begin{tabular}{|c|c|c|}
\hline Nomenclature & $R_{\min }(\mathrm{m})$ & $\begin{array}{l}\text { distance from first heliostats to the tower } \\
\text { working temperature of the combustion chamber }\end{array}$ \\
\hline$A_{a}\left(\mathrm{~m}^{2}\right)$ aperture area of the field & $r_{\mathrm{p}}$ & overall pressure ratio \\
\hline$A H\left(\mathrm{~m}^{2}\right)$ heliostats area & $T_{\mathrm{HS}}(\mathrm{K})$ & working temperature of the solar collector \\
\hline C concentration ratio & THT (m) & tower height \\
\hline$C_{\mathrm{dec}}$ (USD) decommissioning costs & $T_{\mathrm{L}}(\mathrm{K})$ & ambient temperature \\
\hline$C_{\text {inv }}$ (USD) investment and initial installation costs & \multirow[t]{2}{*}{$T_{x}(\mathrm{~K})$} & working fluid temperature after the heat input from the \\
\hline$C_{\mathrm{OML}}(\mathrm{USD} /$ year) operation, maintenance and labour costs & & recuperator \\
\hline $\begin{array}{l}\cos \omega \quad \operatorname{cosine} \text { of Sun radiation angle of incidence } \\
c_{\mathrm{w}}(\mathrm{J} / \mathrm{kg} . \mathrm{K}) \quad \text { specific heat of the working fluid }\end{array}$ & $T_{x^{\prime}}(\mathrm{K})$ & $\begin{array}{l}\text { working fluid temperature after heat input from the solar } \\
\text { collector }\end{array}$ \\
\hline$D R(\mathrm{~m}) \quad$ receiver diameter & $T_{3}(\mathrm{~K})$ & turbine inlet temperature \\
\hline$D S(\mathrm{~m}) \quad$ safety distance between heliostats & \multicolumn{2}{|c|}{$\bar{U}_{\mathrm{L}}\left(\mathrm{W} / \mathrm{m}^{2} \mathrm{~K}\right)$ effective conduction- } \\
\hline$E_{\text {net }}(\mathrm{GWh} /$ year $)$ net energy produced in a year & 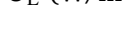 & parameter \\
\hline f solar share & $\alpha$ & effective emissivity of the receiver \\
\hline attenuation factor & \multirow{2}{*}{$\begin{array}{l}\varepsilon_{\mathrm{HC}} \\
\varepsilon_{\mathrm{HS}}\end{array}$} & combustion chamber heat exchanger effectiveness \\
\hline blocking factor & & solar collector heat exchanger effectiveness \\
\hline shadowing factor & $\varepsilon_{\mathrm{c}}$ & isentropic efficiency of the compressor \\
\hline$f_{\mathrm{sp}} \quad$ spillage factor & $\varepsilon_{\mathrm{r}}$ & recuperator effectiveness \\
\hline$G\left(\mathrm{~W} / \mathrm{m}^{2}\right)$ direct normal irradiance & $\varepsilon_{\mathrm{t}}$ & isentropic efficiency of the turbine \\
\hline$i(\%) \quad$ interest rate & & overall thermal efficiency \\
\hline$\dot{m}(\mathrm{~kg} / \mathrm{s})$ mass flow rate of the working substance & & combustion chamber efficiency \\
\hline$\dot{m}_{\mathrm{f}}(\mathrm{kg} / \mathrm{s})$ fuel mass flow rate & $\eta_{\text {gen }}$ & electrical generator efficiency \\
\hline$n_{\text {con }}$ (year) number of years expended in plant construction & $\eta_{\mathrm{H}}$ & thermal efficiency of the Brayton heat engine \\
\hline$n_{\mathrm{dec}}$ (year) number of years expended in plant decommissioning & $\eta_{\mathrm{hel}_{i}}$ & efficiency of heliostat $i$ \\
\hline$n_{\text {op }}$ (year) number of years of plant operation & & solar subsystem efficiency (field and receiver) \\
\hline $\mathrm{NH} \quad$ number of heliostats in the field & \multirow{2}{*}{$\begin{array}{l}\eta_{0} \\
\sigma\left(\mathrm{W} / \mathrm{m}^{2} \mathrm{~K}\right.\end{array}$} & heliostat field optical efficiency \\
\hline$P(\mathrm{MW}) \quad$ power output & & $\left.K^{4}\right)$ Stefan-Boltzmann constant \\
\hline$\dot{Q}_{\mathrm{H}} \mid(\mathrm{J} / \mathrm{s})$ total heat transfer rate absorbed by the working fluid & $\rho$ & mirrors reflectivity \\
\hline$\dot{Q}_{\mathrm{HC}}(\mathrm{J} / \mathrm{s})$ heat rate input from the combustion chamber & Acronyms & \\
\hline \multirow{4}{*}{$\begin{array}{l}\left|\dot{Q}_{\mathrm{HS}}\right|(\mathrm{J} / \mathrm{s}) \text { heat rate input from the solar collector } \\
\left|\dot{Q}_{\mathrm{L}}\right|(\mathrm{J} / \mathrm{s}) \text { heat-transfer rate between the working fluid and the } \\
\text { ambient }\end{array}$} & $\operatorname{CSP}$ & Concentrated Solar Power \\
\hline & DNI & Direct Normal Irradiance \\
\hline & \multirow{2}{*}{$\begin{array}{l}\text { LCoE } \\
\text { OML }\end{array}$} & Levelized Cost of Electricity \\
\hline & & Operation, Maintenance and Labour \\
\hline$Q_{\mathrm{LHV}}(\mathrm{J} / \mathrm{kg})$ lower heating value of the fuel & & \\
\hline
\end{tabular}

physical meaning of the parameters and the main assumptions to perform. In this way, it is possible to have a broad outlook of the overall installation and to locate the main bottlenecks in efficiencies or thermoeconomic indicators. And thus, to suggest improved plant layouts for better performance, reduced consumption, and reduced costs, with the final aim to produce clean electricity at affordable prices.

This study proposes to analyze a central tower thermosolar plant powered by a hybrid Brayton cycle. A first prototype plant at precommercial scale (about $5 \mathrm{MW}$ ) was developed at the south of Spain in the last years. The project was called SOLUGAS and was led by the company Abengoa Solar [21]. This project has served as a reference to test several theoretical and simulation models. It will be taken also in this study as a reference to size the simulated plant for numerical computations.

As operation objective of the plant, it will be taken to deliver an approximately constant electric power to the grid. To get this aim, a hybridization strategy is followed: the turbine inlet temperature is assumed as constant and a combustion chamber burning natural gas releases the heat necessary to reach that temperature even by night or in periods of poor insolation [22].

During the last years our research group has developed from scratch a simulation model for this kind of plants. The model considers the plant as a whole, incorporating its main subsystems. First, a thermodynamic model for a gas turbine was established. It starts from a closed irreversible Brayton-like cycle, which includes the most significant losses in this kind of power units as non-isentropic compressors and turbines, pressure drops in heat input and heat release, and non-ideal recuperation [23]. The model relies on a relatively reduced number of parameters with a clear physical meaning and was validated by comparing with different real engines $[24,25]$. The model was also extended for multi-stage gas turbines with an arbitrary number of compression or/and expansion steps and different working fluids [26].

Second, more recently a detailed model for the solar subsystem, including heliostat field and receiver was developed [25]. This model is capable to predict the optical efficiency of the heliostat field at any time and any meteorological condition. The solar sub-model was tested against the heliostat field GEMASOLAR, located near Seville, Spain [27]. Shadowing and blocking effects were assumed as a constant factor in order to speed up computational calculations, because the aim of the sub-model is to be integrated with that of the power unit and thus, to make predictions for the whole plant. It was checked that this assumption does not lead to appreciable errors by comparing with the software Campo Code developed by Collado et al. [28,29].

The model for the overall plant integrates all sub-models and allow precise and computationally fast estimations of plant performance under different conditions. Thus, the specific objectives of this work can be summarized as follows: (i) To analyze the influence over the whole plant of recuperation in the Brayton cycle from a thermo-economic viewpoint; (ii) To analyze plant performance and LCoE values for two different locations in Spain, one of them well-known from the viewpoint of thermosolar installations and other at a northern latitude with slightly worse solar records but with smaller ambient average temperatures; and (iii) To perform a sensitivity analysis of the effect on thermo-economic records of the main plant design parameters. These include variables 
from the heliostat field, the receiver and the power unit itself.

\section{Model layout}

The involved thermosolar hybrid power plant has three main subsystems: solar field and receiver, combustion chamber, and heat engine; as it can be observed in Fig. 1. A central tower surrounded by a polar (or north) heliostat field together with a solar receiver constitute the first subsystem. The solar subsystem provides heat input to a gas turbine that is coupled to a combustion chamber which ensures to reach a fixed turbine inlet temperature by night or during cloudy periods or other bad meteorological conditions. Proceeding in this way, the power output is approximately constant, which is the operation aim of the installation.

The overall thermal efficiency of the system, $\eta$, is defined as the net power output divided by the total heat input [30]:

$\eta=\frac{P}{G A_{\mathrm{a}}+\dot{m}_{f} Q_{\mathrm{LHV}}}$

Total heat input is made up of the solar heat ( $G A_{\mathrm{a}}$ where $G$ is the direct normal irradiance and $A_{\mathrm{a}}$ the aperture area) and the heat from fuel combustion ( $\dot{m}_{\mathrm{f}} Q_{\mathrm{LHV}}$ where $\dot{m}_{\mathrm{f}}$ is the instantaneous fuel mass flow and $Q_{\mathrm{LHV}}$ the lower heating value of the fuel). Overall efficiency can be expressed as a function of the subsystems efficiencies. This means: in terms of the heat engine efficiency, $\eta_{\mathrm{H}}$; solar subsystem efficiency, $\eta_{\mathrm{S}}$; combustion efficiency, $\eta_{\mathrm{C}}$; the effectivenesses of the heat exchangers associated with the solar collector, $\varepsilon_{\mathrm{HS}}$, and to the combustion chamber, $\varepsilon_{\mathrm{HC}}$; and finally, the solar share, $f$ (ratio of solar heat input over the total heat input) [23]. Explicit calculations can be found in that paper. The relationship among overall efficiency and subsystems efficiencies can be expressed as [23]:

$\eta=\eta_{\mathrm{S}} \eta_{\mathrm{C}} \eta_{\mathrm{H}}\left[\frac{\varepsilon_{\mathrm{HS}} \varepsilon_{\mathrm{HC}}}{\eta_{\mathrm{C}} \varepsilon_{\mathrm{HC}} f+\eta_{\mathrm{S}} \varepsilon_{\mathrm{HS}}(1-f)}\right]$

In the next subsections the models for subsystems efficiencies are detailed.

\subsection{Thermodynamic model for the power unit}

The thermodynamic model for the power unit, a Brayton-like gas turbine was developed by our group in previous works, so only a brief summary with the main assumptions is reported here [23,31]. It is assumed that a mass rate of an ideal gas, $\dot{m}$, with temperature dependent specific heat, $c_{\mathrm{w}}(T)$, develops an irreversible closed Brayton cycle. Recuperation can be included in the cycle. The working temperature of

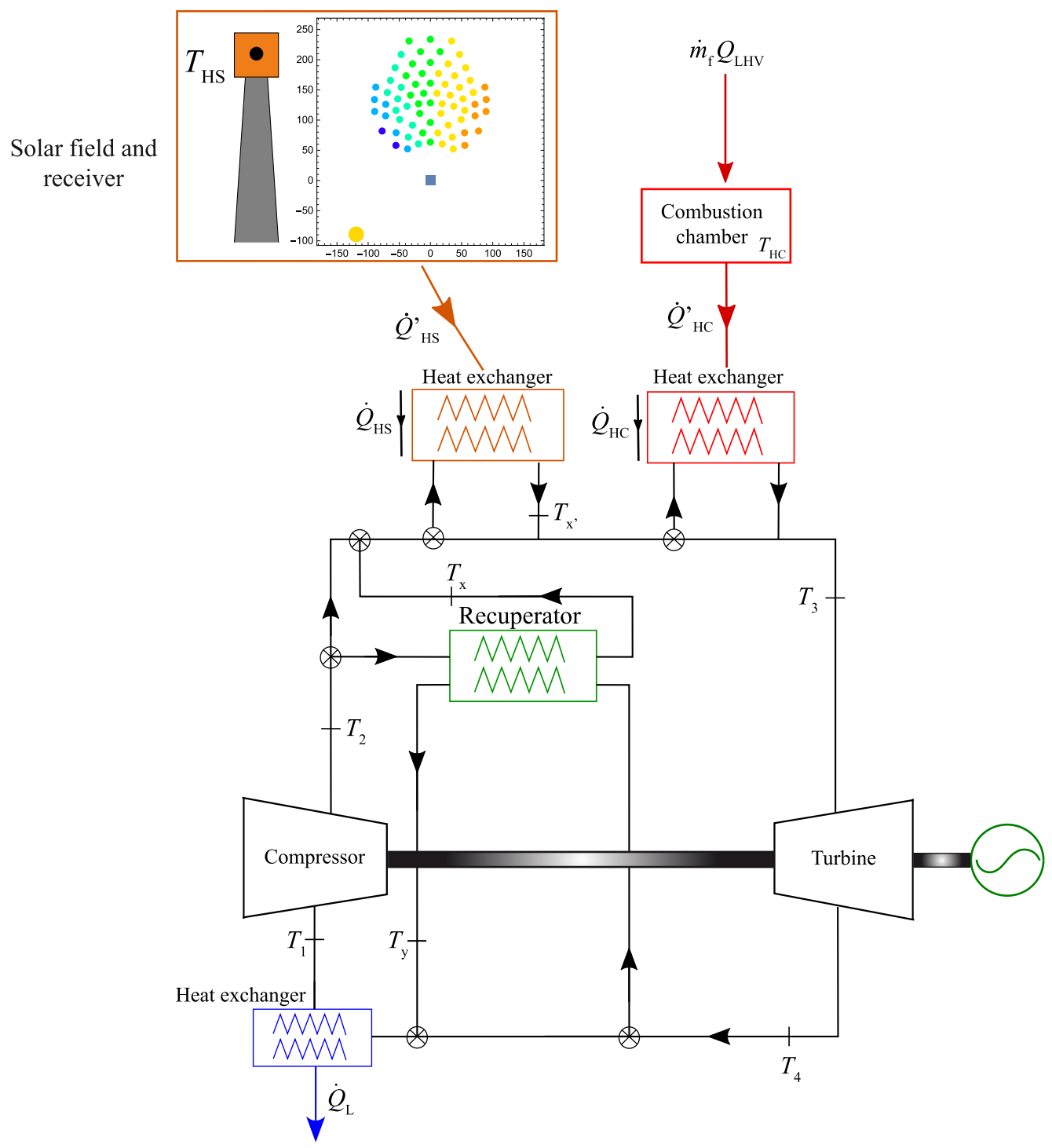

Fig. 1. Plant diagram with the main subsystems: solar field and receiver, combustion chamber, and heat engine (gas turbine). 
the solar receiver, $T_{\mathrm{HS}}$, and that of the surroundings, $T_{\mathrm{L}}$, are fluctuating quantities.

1. First, the gas is compressed by means of a non-ideal compressor. Its isentropic efficiency is given by $\varepsilon_{\mathrm{c}}$ and measures how far is the compressor from ideal adiabatic operation. Temperature at compressor inlet is denoted $T_{1}$ and at the exit, $T_{2}$. An explicit $T-S$ scheme of the cycle with the same notation can be found in [31].

2. After compression, the gas sequentially receives three energy inputs. First, the non-ideal recuperator, when considered in plant layout, increases the gas temperature from $T_{2}$ to $T_{x}$. Its effectiveness, $\varepsilon_{\mathrm{r}}$, is defined as the ratio between the actual temperature increase and the maximum ideal one. In the case of a non-recuperative cycle, $\varepsilon_{\mathrm{r}}=0$, and in the ideal limit, $\varepsilon_{\mathrm{r}}=1$.

Secondly, the gas receives a heat flow, $\left|\dot{Q}_{\mathrm{HS}}\right|$, from the solar subsystem and thus, its temperature increases from $T_{x}$ to $T_{x^{\prime}}$. The latter is the working fluid temperature at the solar receiver outlet. From the viewpoint of the heat engine, the solar receiver acts as a heat exchanger with effectiveness, $\varepsilon_{\mathrm{HS}}$. If $T_{x^{\prime}}$ is below the target turbine inlet temperature, denoted as $T_{3}$, the gas receives a final heat input from the combustion chamber in order to ensure an approximately constant, $T_{3}$, independently of the value of direct irradiance, $G$. Similarly, as a closed cycle is being considered, the combustion chamber is represented as a heat exchanger with effectiveness, $\varepsilon_{\mathrm{HC}}$. In which respect to the pressure during the heat addition processes, a global parameter quantifies the pressure decrease in the whole heat input process. In real plants, pressure decays are associated with the particular equipment in any of the three steps of the heat input process, but the consideration of a unique global pressure decay parameter allows to obtain analytical equations and to numerically check the effects of pressure decays in the output parameters of the plant [32].

3. At the turbine inlet, the working fluid has reached its maximum temperature and it is expanded by means of a non-ideal turbine characterized by an isentropic efficiency, $\varepsilon_{\mathrm{t}}$. Temperature at the outlet is denoted $T_{4}$.

4. The final heat release to recover compressor inlet conditions is divided into two steps. First, through recuperation and later on by exchanging heat to the ambient through a non-ideal heat exchanger with effectiveness, $\varepsilon_{\mathrm{L}}$. The pressure loss during the whole heat release process is measured through a unique coefficient that accounts for the relative pressure decay.

It is convenient to define a global pressure ratio, $r_{\mathrm{p}}$ as:

$$
r_{\mathrm{p}}=\frac{p_{\mathrm{H}}}{p_{\mathrm{L}}-\Delta p_{\mathrm{L}}}
$$

where $p_{\mathrm{H}}$ is the highest pressure in the cycle (at compressor exit) and $p_{\mathrm{L}}-\Delta p_{\mathrm{L}}$ is the lowest one, at compressor entrance. In this equation, $p_{\mathrm{L}}$ represents pressure at turbine exit.

Once the main hypotheses and parameters have been established, the temperatures of all the states in the cycle can be expressed in terms of the temperature of the solar collector, $T_{\mathrm{HS}}$, that of the combustion chamber, $T_{\mathrm{HC}}$, the pressure ratios of the compressor, and the parameters that characterize the non-ideality of the components. The explicit set of equations can be found in [31]. The total heat input rate, $\left|\dot{Q}_{\mathrm{H}}\right|$, and, the heat release, $\left|\dot{Q}_{\mathrm{L}}\right|$, are expressed in terms of the temperatures as:

$\left|\dot{Q}_{H}\right|=\left|\dot{Q}_{\mathrm{HS}}\right|+\left|\dot{Q}_{\mathrm{HC}}\right|$

$\left|\dot{Q}_{L}\right|=\dot{m} \int_{T_{1}}^{T_{y}} c_{\mathrm{w}}(T) d T$

where,
$\left|\dot{Q}_{\mathrm{HS}}\right|=\dot{m} \int_{T_{x}}^{T_{x^{\prime}}} c_{\mathrm{w}}(T) d T=f\left|\dot{Q}_{\mathrm{H}}\right|$

$\left|\dot{Q}_{\mathrm{HC}}\right|=\dot{m} \int_{T_{x^{\prime}}}^{T_{3}} c_{\mathrm{w}}(T) d T=(1-f)\left|\dot{Q}_{\mathrm{H}}\right|$

Thus, the power output released by the heat engine is, $P=\left|\dot{Q}_{\mathrm{H}}\right|-\left|\dot{Q}_{\mathrm{L}}\right|$, and its thermal efficiency, $\eta_{\mathrm{H}}=P /\left|\dot{Q}_{\mathrm{H}}\right|$. This sub-model for the power unit efficiency is incorporated then to calculate the overall efficiency through Eq. (2).

\subsection{Heliostat field and receiver models}

The considered heliostat field can be circular or polar around the central tower. The numerical application in the next sections would be developed for a polar one but the approach is similar. The heliostat field is made up of several rows of heliostats, each with a two-axis tracking to improve irradiance receiving and reflection towards the tower. The heliostat surface is a rectangular plane mirror. A safety distance between heliostats, $D S$, is considered [33].

Heliostats are placed uniformly over a circumference. The heliostat field is divided into regions and rows. A region comprises one or more rows in which the increment of the azimuth angle is constant [33]. For a particular region, distance between adjacent heliostats increases with the distance to the tower. A new region begins if separation between two heliostats is large enough to set one more heliostat. There are several field expansion techniques in the literature. In this work, Campo Code model was followed $[33,34]$. Particular details on our model can be found in [25]. As in most models, heliostats locations arise from decreasing the heliostat density from an initial dense layout. Because of shadowing and blocking effects (explained below) there is a balance effect and optimum densities are found because field expansion advantages prevail over its disadvantages. In this work, heliostat densities were calculated as in a preliminar version of Campo Code [33].

The optical efficiency of the whole field, $\eta_{0}$, is the average of the efficiency of each heliostat:

$\eta_{0}=\bar{\eta}_{\text {hel }}=\frac{\sum_{i=1}^{N H} \eta_{\mathrm{hel}_{i}}}{N H}$

where $\mathrm{NH}$ represents the total number of heliostats in the solar field. The optical efficiency of each one is a product of losses factors:

$\eta_{\text {hel }_{i}}=\cos \omega_{i} \cdot f_{\mathrm{sp}, i} \cdot f_{\mathrm{at}, i} \cdot f_{\mathrm{b}} \cdot f_{\mathrm{sh}} \cdot \rho$

In this equation $\cos \omega$ denotes the cosine of Sun radiation angle of incidence, $f_{\mathrm{sp}}$ comes from spillage, $f_{\mathrm{at}}$ is the attenuation factor, $f_{\mathrm{b}}$ represents the blocking factor, $f_{\mathrm{sh}}$ is the shadowing factor, and $\rho$ represents mirrors reflectivity. A subindex $i$ has been added in those terms that actually depend on each heliostat in our framework. This is explained below.

\section{Cosine factor}

It is the main factor governing optical efficiency. An analytical study on Sun-heliostat-receiver geometry is done on the basis of optical reflection law. This leads to an expression for $\omega$ that depends on each heliostat coordinates, receiver coordinates, and solar azimuth and altitude angles. An explicit equation for $\omega$ can be found in [33].

2. Spillage factor

The fraction of reflected radiation outside the receiver limits is the origin of spillage losses factor The power delivered by each heliostat to the receiver is the integral over the receiver aperture area of the corresponding flux density function. In this work it is assumed the spillage calculation model by HFLCAL [10]. Spillage is considered as 
dependent on the dimensions of the receiver, heliostat area, the effective dispersion of the sun shape on the receiver plane, heliostat tracking, and surface errors. Our formulation is the same that the one proposed by Collado and Guallar in [29], but without taking into account the astigmatic effect. This makes the spillage factor depend on each heliostat position with respect to the receiver.

\section{Attenuation factor}

This factor arises from the energy dissipation due to absorption of air molecules in the region between the heliostats and the receiver. So, it depends on the distance between the centre of each heliostat and the aiming point in the receiver [35]. Therefore, it depends on each particular heliostat. For large solar fields, differences in attenuation among heliostats are larger than in small ones. It is usual to take an empirical formula for $f_{\text {at }}$ in terms of the distance.

4. Blocking and shadowing factors

The blocking factor measures the energy loss because a fraction of the reflected energy from a back heliostat can be stopped by one ahead. Besides, the shadowing factor takes into account the energy loss when a heliostat projects a shadow onto another one. Thus, only a fraction of the surface of the last heliostat reflects sun radiation. The most complex and time consuming components in the numerical evaluation of optical efficiency are these factors [36]. They can be calculated one by one, for each heliostat, with different techniques or, in order to avoid extensive calculations [37], to take them as constant for certain purposes. As the main objective of this work is to analyze the plant as a whole, including all subsystems, these factors will be taken as constant. A posteriori sensitivity analysis will justify this assumption.

\section{Mirror reflectivity}

The actual reflectivity, $\rho$, is usually taken as the simple product of two factors: the nominal reflectivity and the nominal cleanliness [29]. The importance of the actual reflectivity is not just related to the efficiency of the heliostat, indeed, it is also a function of the maintenance cost of the field since the nominal cleanliness depends on plant maintenance works.

As a summary, it should be noted that cosine factor, spillage, and attenuation depend on the particular heliostat. The other factors (blocking, shadowing, and reflectivity) are independent and so, are common factors in the average optical efficiency (see Eq. (8)).

All the losses above are optical in nature and arise from the collection of the solar power from the heliostats and its transfer through specular reflection to the receiver aperture. Nevertheless, the receiver as any body at high temperature has losses due to heat transfer to the surroundings because of conduction, convection, and radiation. In this way, it is usual to express the joint solar subsystem efficiency, $\eta_{\mathrm{S}}$, as $[26,30]$ :

$\eta_{\mathrm{S}}=\eta_{0}-\frac{1}{G C}\left[\alpha \sigma\left(T_{\mathrm{HS}}^{4}-T_{\mathrm{L}}^{4}\right)+\bar{U}_{L}\left(T_{\mathrm{HS}}-T_{\mathrm{L}}\right)\right]$

where $C$ is the concentration ratio, $\alpha$ the emissivity of the receiver surface, $\sigma$ the Stefan-Boltzmann constant, and $\bar{U}_{\mathrm{L}}$ the overall conduction and convection heat transfer coefficient. As stated before, $T_{\mathrm{HS}}$ is the solar collector operation temperature and $T_{\mathrm{L}}$ the ambient temperature. From the thermodynamic viewpoint $T_{\mathrm{HS}}$ is an equilibrium temperature between the heat input in the receiver from the solar field and the heat release from the receiver to the working fluid. Within this scheme, the heat flux actually absorbed by the working fluid is: $\left|\dot{Q}_{\mathrm{HS}}\right|=\varepsilon_{\mathrm{HS}} G A_{\mathrm{a}} \eta_{\mathrm{S}}$.

In an analogous way, in those periods where the combustion chamber is required to guarantee an stable turbine inlet temperature, the heat flow from combustion is expressed as $\left|\dot{Q}_{\mathrm{HC}}\right|=\varepsilon_{\mathrm{HC}} \dot{m}_{\mathrm{f}} Q_{\mathrm{LHV}} \eta_{\mathrm{C}}$. In this expression $\varepsilon_{\mathrm{HC}}$ is the effectiveness of the heat exchanger associated with the combustion chamber (because the thermodynamic cycle is closed and, so, combustion is external) and $\eta_{\mathrm{C}}$ arises from combustion inefficiencies. It is usual to take it as a constant factor. This avoids the consideration of specific combustion and chemical reactions models.

\section{Thermo-economic performance}

A thermo-economic model has been implemented in our simulations with the purpose of analyzing system viability. The levelized cost of electricity (LCoE), represents the minimum sale price at which the electricity should be sold for the plant to be profitable during a specified length of time. It is probably the simplest and most common economic indicator. As commented by Dowling et al. [38], it can be criticized because it does not capture the time-varying value of electricity. Particularly, LCoE comparison within different concentrating solar power (CSP) technologies maybe subtle. Certain design modifications can, a priori, increase LCoE, but at the same time can lead to short pay-off periods when time varying electricity prices are considered. In any case, it is difficult to make precise estimations on costs and adequate sale prices for technologies that are still under development. Absolute numerical estimations should be taken with care, however comparison between different plant designs and sensitivity analysis under the same assumptions can certainly lead to robust conclusions. A detailed review on these issues in the case of PV and CSP systems is due to HernándezMoro et al. [39].

In this work the formulation of Spelling [40] for the estimation of LCoE will be assumed. Its definition can be written as:

$\mathrm{LCoE}=\frac{\beta_{\text {inv }} C_{\text {inv }}+\beta_{\mathrm{dec}} C_{\mathrm{dec}}+C_{\mathrm{OML}}}{E_{\text {net }}}$

where $C_{\text {inv }}$ represents the investment and initial installation costs, $C_{\text {dec }}$ the decommissioning costs, and $C_{\mathrm{OML}}$ the operation, maintenance and labour costs (OML), that include fuel consumption in the case of hybrid plants as the one considered here. All these terms are yearly costs. The denominator, $E_{\text {net }}$, stands for the annual net energy output of the plant. The weight $\beta_{\text {inv }}$ relates the total capital investment costs to the equivalent annual payments over a fixed period of years. Similarly, $\beta_{\mathrm{dec}}$ represents the yearly equivalent cost of decommissioning. These factors can be written as [40]:

$\beta_{\text {inv }}=\frac{(1+i)^{n_{\mathrm{con}}}-1}{i \cdot n_{\mathrm{con}}} \frac{i(1+i)^{n_{\mathrm{op}}}}{(1+i)^{n_{\mathrm{op}}}-1}+k_{\mathrm{ins}}$

$\beta_{\mathrm{dec}}=\frac{(1+i)^{n_{\mathrm{dec}}}-1}{i \cdot n_{\mathrm{dec}}(1+i)^{n_{\mathrm{dec}}-1}} \frac{i}{(1+i)^{n_{\mathrm{op}}}-1}$

In these equations $i$ is the real interest rate and $k_{\text {ins }}$, the annual plant insurance rate. The number of years expended in plant construction, operation, and decommissioning are denoted, $n_{\mathrm{con}}, n_{\mathrm{op}}$, and $n_{\mathrm{dec}}$, respectively. Thus, this formulation of $\mathrm{LCoE}$ explicitly considers the time spent during construction and decommissioning. In other formulations these times are considered as one year, but in this case these times could be longer. Fig. 2 depicts in a tree shape all the terms considered for LCoE computation.

\section{Model implementation}

The theoretical model summarized in the last section has been implemented in our own software, developed in programming language Mathematica ${ }^{\circledR}$. Values of solar and gas turbine parameters are very similar to SOLUGAS plant features [21]. This project was developed by Abengoa Solar in Sanlúcar la Mayor, near Seville (Spain). As in our simulation, the plant is made up of a polar heliostats field focusing on a cavity receiver atop a central tower, where pressurized air develops a recuperated Brayton cycle.

\subsection{Heliostat field and power unit data}

The most significant data from the heliostats field are collected in 


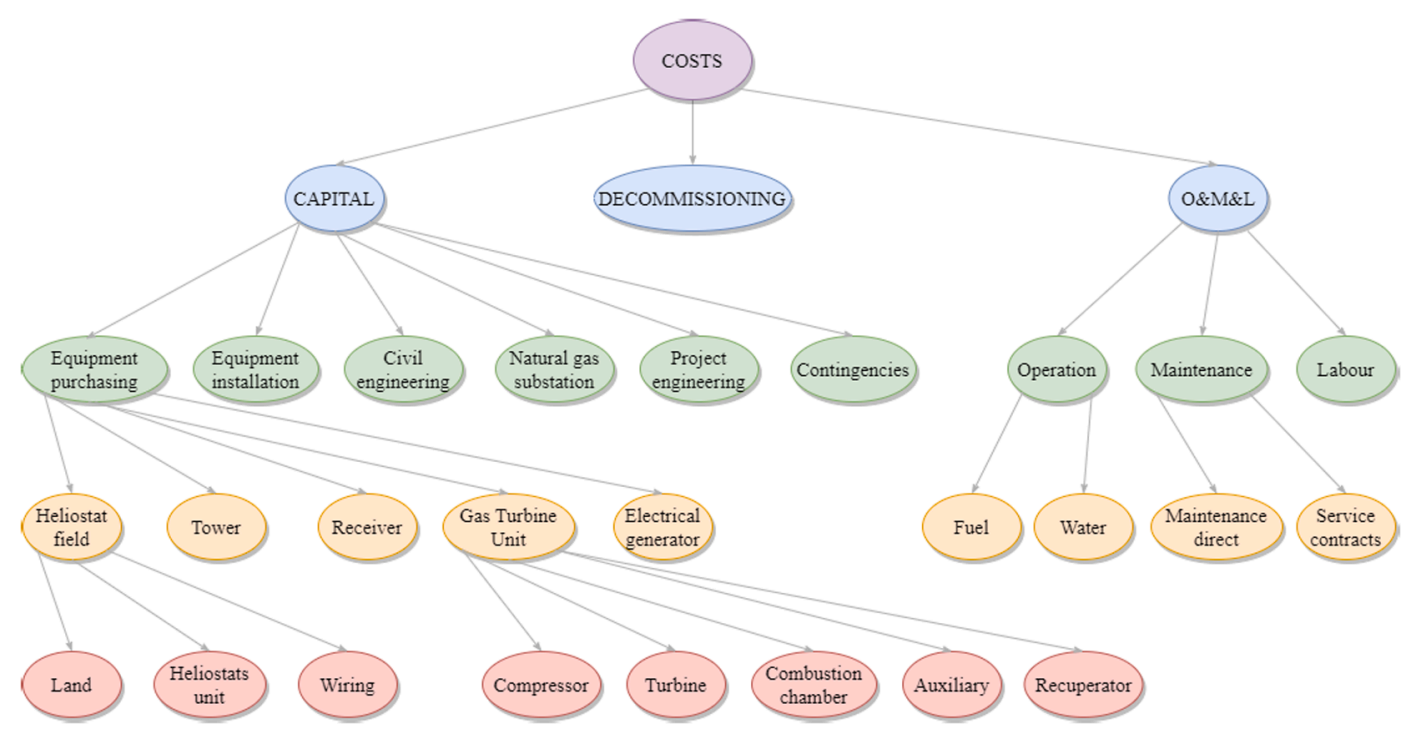

Fig. 2. Tree structure of all the costs considered for the calculation of LCoE.

Table 1

Parameters for the solar field and receiver were taken from SOLUGAS project data [21] and those for the Brayton cycle correspond to the turbine Mercury 50 [41]. Those marked with * were assumed from [42] where the numerical model for the gas turbine was validated.

\begin{tabular}{|c|c|c|c|c|}
\hline Subsystem & Parameter & Symbol & Value & Unit \\
\hline \multirow{17}{*}{$\begin{array}{l}\text { Heliostat } \\
\text { field and } \\
\text { receiver }\end{array}$} & Tower height & THT & 65 & $\mathrm{~m}$ \\
\hline & Heliostats number & $N H$ & 70 & - \\
\hline & Heliostat height & $L H$ & 11.01 & $\mathrm{~m}$ \\
\hline & Safety distance & $D S$ & 0.3 & $\mathrm{LH}$ \\
\hline & Heliostat area & $A H$ & 121.3 & $\mathrm{~m}^{2}$ \\
\hline & Adjacent heliostats separation & - & 3.285 & $\mathrm{~m}$ \\
\hline & First row distance from tower & $R_{\min }$ & 64 & $\mathrm{~m}$ \\
\hline & Concentration ratio & $C$ & 432 & - \\
\hline & Blocking and shadowing factor & $f_{\mathrm{b}} \cdot f_{\mathrm{sh}}$ & 0.95 & - \\
\hline & Actual mirrors reflectivity & $\rho$ & 0.836 & - \\
\hline & Sun shape deviation & - & 2.51 & mrad \\
\hline & Surface errors deviation & - & 0.94 & $\operatorname{mrad}$ \\
\hline & Tracking errors deviation & - & 0.63 & $\operatorname{mrad}$ \\
\hline & Receiver diameter & $D R$ & 5 & $\mathrm{~m}$ \\
\hline & Receiver emissivity* & $\alpha$ & 0.1 & - \\
\hline & $\begin{array}{l}\text { Conduction and convection losses } \\
\text { factor* }\end{array}$ & $\bar{U}_{\mathrm{L}}$ & 5 & $\mathrm{~W} /\left(\mathrm{m}^{2} \mathrm{~K}\right)$ \\
\hline & Receiver effectiveness* & $\varepsilon_{\mathrm{HS}}$ & 0.78 & - \\
\hline \multirow{2}{*}{$\begin{array}{l}\text { Combustion } \\
\text { system }\end{array}$} & Combustion chamber efficiency* & $\eta_{\mathrm{C}}$ & 0.98 & - \\
\hline & Heat exchanger efficiency* & $\varepsilon_{\mathrm{HC}}$ & 0.98 & - \\
\hline \multirow{8}{*}{$\begin{array}{l}\text { Brayton } \\
\text { cycle }\end{array}$} & Pressure ratio & $r_{\mathrm{p}}$ & 9.9 & \\
\hline & Air mass flow & $\dot{m}$ & 17.9 & $\mathrm{~kg} / \mathrm{s}$ \\
\hline & Turbine isentropic efficiency* & $\varepsilon_{\mathrm{t}}$ & 0.885 & - \\
\hline & Compressor isentropic efficiency* & $\varepsilon_{\mathrm{c}}$ & 0.77 & - \\
\hline & Turbine inlet temperature* & $T_{3}$ & 1423 & $\mathrm{~K}$ \\
\hline & Recuperator effectiveness* & $\varepsilon_{\mathrm{r}}$ & 0.775 & - \\
\hline & Heat input pressure drop* & $\Delta p_{\mathrm{H}} / p_{\mathrm{H}}$ & 9.2 & $\%$ \\
\hline & Generator efficiency* & $\eta_{\text {gen }}$ & 0.99 & - \\
\hline
\end{tabular}

Table 1. SOLUGAS field is made up of 70 square heliostats of $121.3 \mathrm{~m}^{2}$ area. They are placed with polar symmetry with respect to the receiver, located on the central tower at a height of $65 \mathrm{~m}$ at the south of the field. The distances of all heliostats to the receiver are below $1 \mathrm{~km}$ and the formula by Leary and Hankins [43] for the attenuation factor, $f_{\text {at }}$, is assumed.

Meteorological data are taken from Spanish Meteorological National
Agency (AEMET) [44], except for solar irradiance which has been obtained from Copernicus Atmosphere Monitoring Service (CAMS) [45]. Annual averages of ambient temperatures and direct normal irradiance were made by taking one representative day of each season (taking real data for that day) and weighting each one with the number of days corresponding to each season.

Our code for heliostat field efficiency calculation has been validated by comparing against Campo Code software $[29,33]$, not only at design conditions but also seasonally. Deviations in average optical efficiency, $\eta_{0}$, and all its components are always below $1 \%$. The power unit used in SOLUGAS is the Mercury 50 gas turbine by Caterpillar [41]. It delivers 4.6 MW of nominal power output, with a pressure ratio of 9.9 and an air mass flow of $17.9 \mathrm{~kg} / \mathrm{s}$. Further details on Brayton cycle numerical features and its validation are gathered in [42] (see Tables 1 and 2 of that paper), [26] (Section 3.1), and [25] (see Appendix B). Numerical data for all the subsystems in the particular case of the SOLUGAS project are compiled in Table 1 . The particular value of the effective convective heat transfer coefficient $\bar{U}_{\mathrm{L}}$ for the receiver was taken from [30].

\subsection{Data for the computation of $L C O E$}

As commented before, the operation aim of the plant is to produce an approximately constant power output during all the year independently of solar conditions. This strategy, on one side, allows for a high capacity factor and a high yearly energy production, but, on the other side, requires a considerable amount of fuel, to keep electricity production by night or during bad solar conditions.

For the thermo-economic analysis, the solar plant is assumed to be operating 25 years with a real interest rate of $7 \%$ and an annual plant insurance rate of $1 \%$. These parameters and other employed in the calculation of LCoE are shown in Tables 2 and 3. Most correlations and numerical data were taken from Spelling's work [40]. Of course, all costs correlations have been adapted as close as possible to the

Table 2

Interest and time parameters assumed for the calculation of LCoE [40].

\begin{tabular}{cccc}
\hline Parameter & Symbol & Value & Unit \\
\hline Real interest rate & $i$ & 7 & $(\%)$ \\
Insurance interest rate & $k_{\text {ins }}$ & 1 & $(\%)$ \\
Construction time & $n_{\text {con }}$ & 2 & year \\
Operation time & $n_{\text {op }}$ & 25 & year \\
Decommissioning time & $n_{\text {dec }}$ & 2 & year \\
\hline
\end{tabular}


Table 3

Costs obtained in the calculation of LCoE. All of them are expressed in Million US dollars except those from OML that are accounted in yearly terms. The numerical values were obtained for the SOLUGAS plant with the costs data commented in the text.

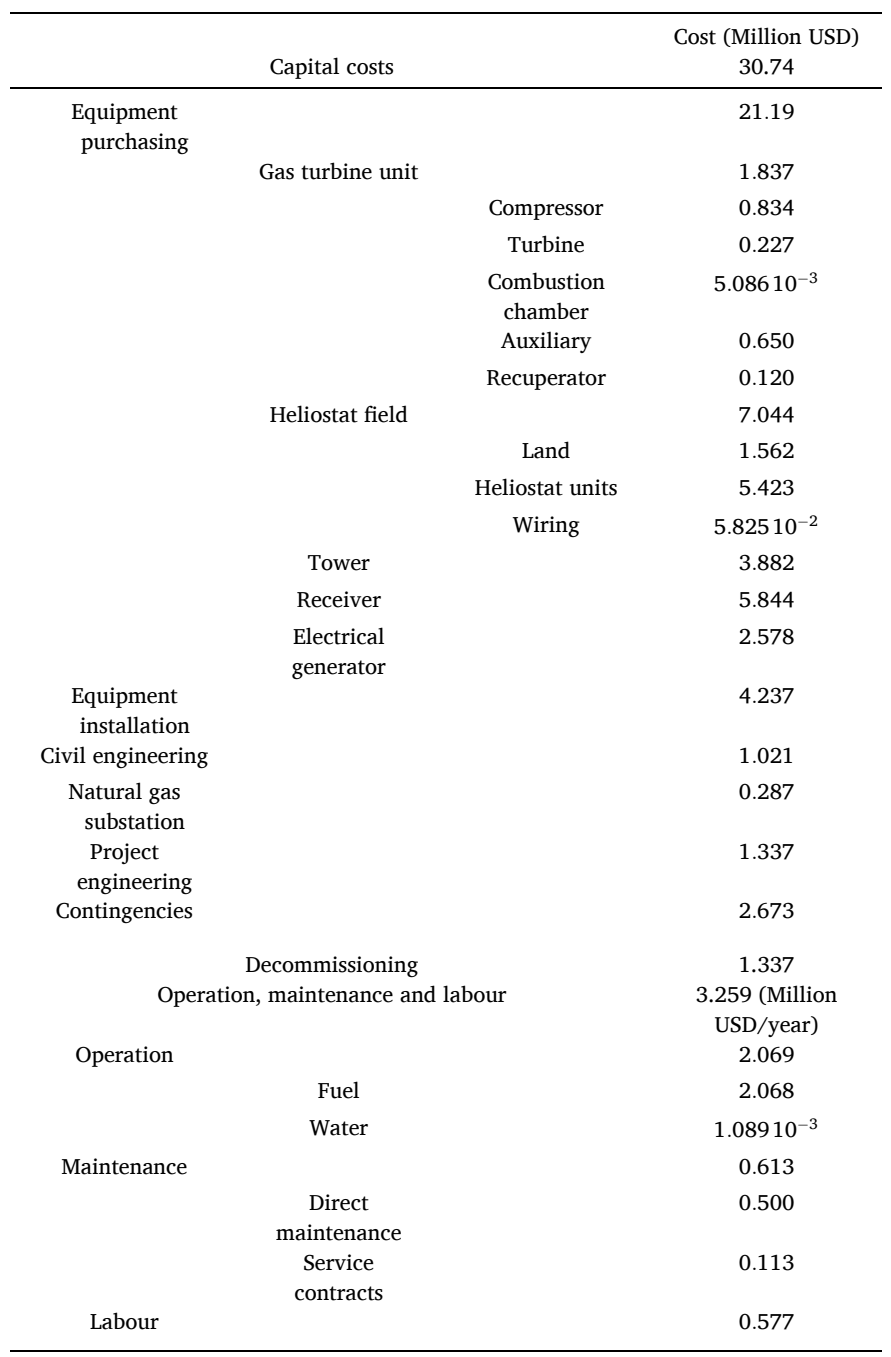

conditions of the particular plant chosen to perform calculations, i.e., SOLUGAS project plant. Capital, decommissioning, and OML costs have been computed following Spelling's work [40]. However, regarding equipment costs, some differences with respect to Spelling work are considered for a more reasonable implementation in our thermodynamic model: the solar receiver cost computation [46] and the addition of the recuperator cost [47]. All equipment purchasing costs have been updated according to Marshall and Swift indexes for taking into account inflation [48].

In order to survey different cost scenarios, pessimistic and optimistic, costs from different works were analyzed. Particularly, it was found that most spread out costs among different studies correspond to prices of receiver and recuperator. Three different scenarios are analyzed in this work: optimistic (both with the cheapest costs $[47,49]$ ), pessimistic (both with the most expensive costs $[46,50]$ ) and intermediate scenario (most expensive receiver [46] and cheapest recuperator [47]). For the sake of conciseness, costs results from our calculations with the data taken in the mentioned references and applied for the case of the SOLUGAS base case are broken down in Table 3 for the intermediate scenario.

Capital costs reach more than 30 Million USD, meanwhile decommissioning and OML take values about 1.3 Million USD and 3.3 Million
USD per year, respectively. Equipment requires about $69 \%$ of all investment costs. And, within equipment purchasing, the solar subsystem (heliostat field, tower and receiver) amounts near $80 \%$. In the case of SOLUGAS, the heliostat field is small (70 heliostats) and so, land investment is also reduced. Land costs are $22.2 \%$ with respect to heliostat field cost. With reference to the gas turbine, it constitutes $8.7 \%$ of all equipment purchasing. Several pie charts with the distribution of costs are shown in Fig. 3. Within OML, fuel expenses are the main factor since the plant works in a hybrid mode the whole time. This is also a consequence of the undersized heliostat field. Here it should be noticed that it was probed before that SOLUGAS solar field is not sized enough for achieving selected turbine inlet temperature even for very good direct normal irradiance (see Fig. 7 in [42]). And so, combustion of natural gas is always required. Therefore, this solar field should be increased in size in order to reach a larger solar share at least at design point [25]. Explicit values of solar share will be shown below.

\section{Numerical estimations of LCoE}

All these ingredients allow to determine the LCoE for the intermediate scenario, which is around $158 \mathrm{USD} / \mathrm{MWh}$ for a recuperated gas turbine. With the purpose of contextualizing this number, a comparison among LCoE values from some papers for different systems has been performed in Fig. 4. Our plant simulation leads to a LCoE that is in the middle region of the interval that can be found in the literature.

It is interesting to comment some of the values shown in Fig. 4. Mohammadi et al. [47] have recently developed a thermo-economic analysis of several multi-stage configurations for a recuperative Brayton power cycle hybridized with a solar tower. The project SOLGATE [59], located at Almería, south of Spain, with a power output about 30 MWe was taken as reference. For the single-stage case an average thermal efficiency of 0.404 and LCoE of 89.53 USD/MWh were predicted. It was also predicted that increasing the number of compressionexpansion stages to 4 , LCoE could decrease to 80.82 USD/MWh. These values are the lowest found in the literature in our survey. They are quite far, by cheaper, from our calculations. Giostri et al. [55] very recently have presented another survey for a different power output scale: a micro gas turbine operating in the range $100-200 \mathrm{kWe}$. The plant was also supposed to be located at Almería, Spain. An interval between 161 and 173 USD/MWh was estimated. The plant design included a recuperator. This interval is quite close to the values obtained in this work. It is also interesting to compare the LCoE of this technology (hybrid central tower with a gas turbine) with a widely commercial one. For instance, in Fig. 4 it is included also a recent study for a plant located in Spain based on parabolic trough with Rankine cycle, thermal storage and natural gas back-up unit for maintenance and start-up operations (in Fig. 4 it is denoted as SanMiguel_18) [54]. Cycle efficiency was estimated about $36.8 \%$ and LCoE interval (depending on natural gas input) between 184 and 200 USD/MW. The interval is slightly over the values found here, in spite of the different technologies and commercial maturity.

\subsection{Influence of recuperation}

A key point in the pre-design of any type of plant based on a gas turbine power unit is the inclusion or not of a recuperator. The main, $a$ priori, positive feature is that recuperation increases cycle thermal efficiency. But from the perspective of the solar subsystem, recuperation increases the mean working temperature of the solar receiver and so, its thermal losses (see, for instance, Fig. 10 in [25]). Moreover, it is evident from the viewpoint of equipment investment, that the recuperator, depending on system size, is an expensive component. Thus, it is interesting to check its influence on LCoE.

Table 4 contains the data for a direct comparison between recuperated and non-recuperated plant layouts. The recuperated plant displays an overall thermal efficiency 0.349 that is almost $28 \%$ over that of the non-recuperated one. This is a consequence of the balance between two 


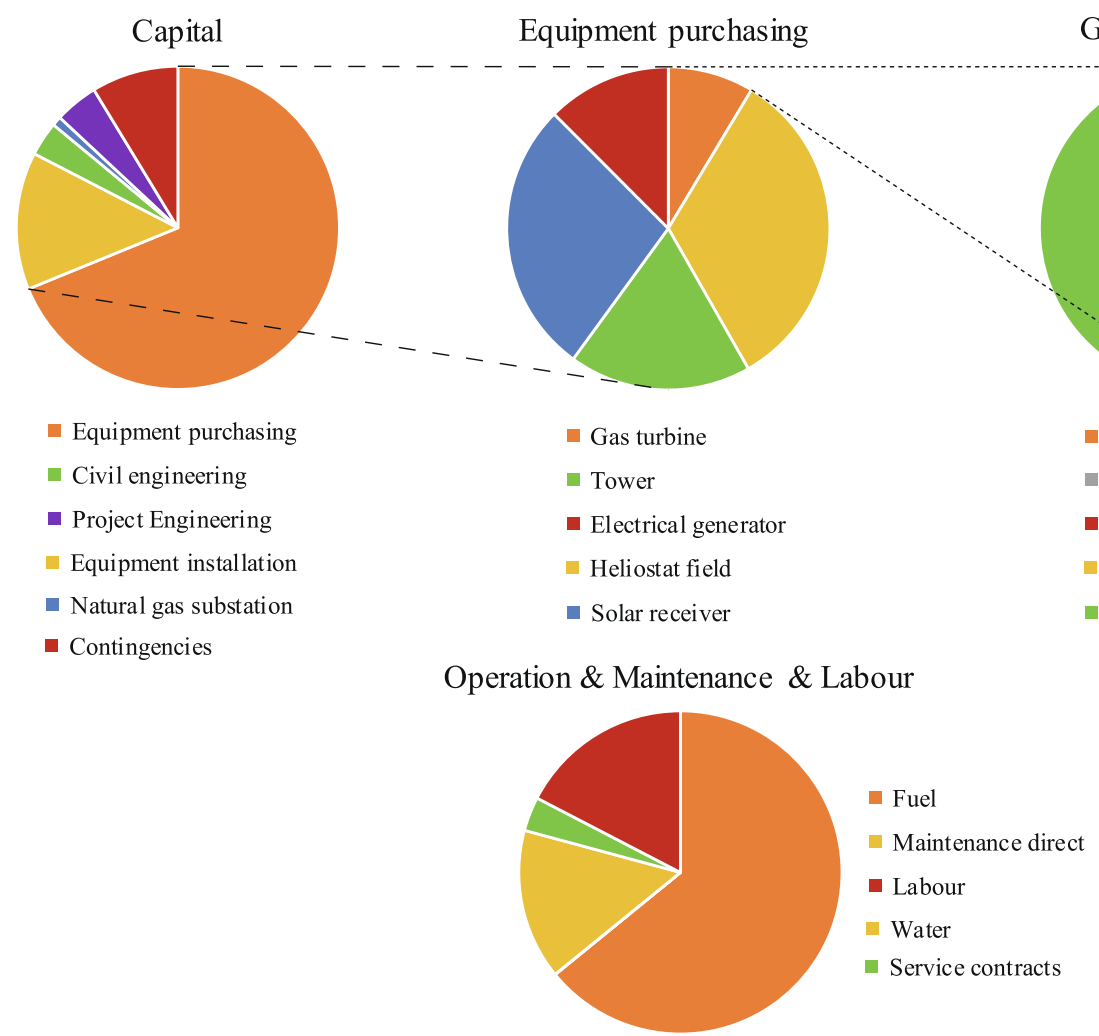

Fig. 3. Pie charts for spared costs distributions for the intermediate scenario. Top: capital, equipment purchasing, and gas turbine unit costs. Bottom image: operation, maintenance, and labour costs.

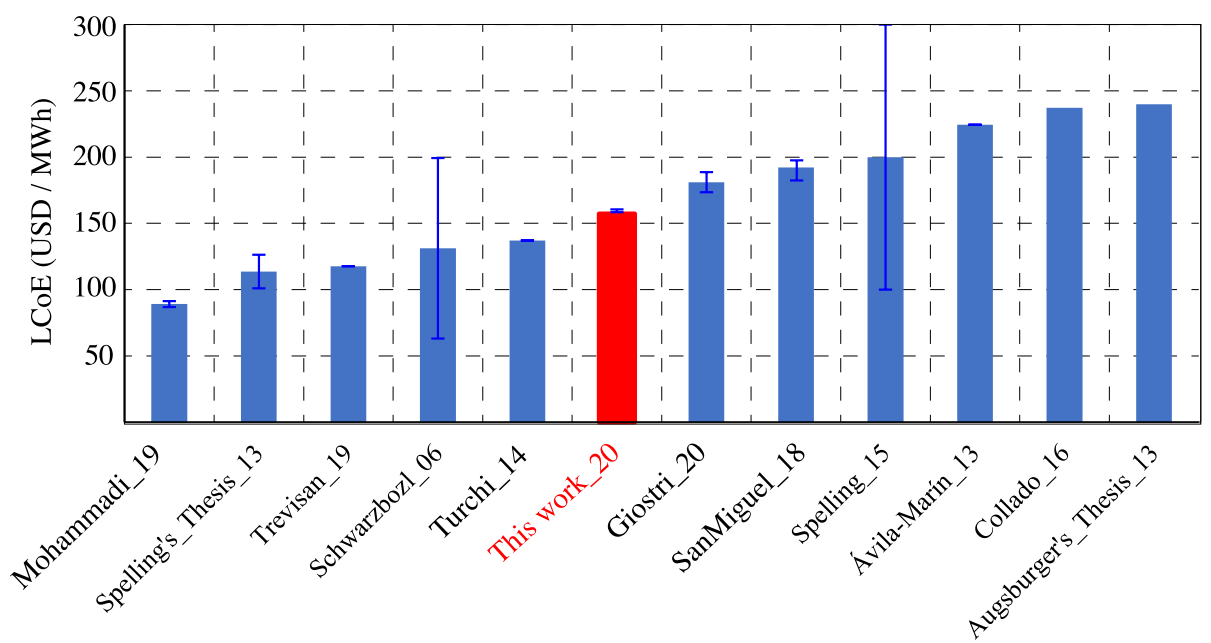

Fig. 4. Comparison of the LCoE obtained in this work (red bar) with other values in the literature $[40,46,47,51-58]$. Error bars are shown when the mentioned references include them.

facts. Thermal engine efficiency, $\eta_{\mathrm{H}}$, is quite larger for the recuperative case, but, on the contrary, the whole solar subsystem efficiency, $\eta_{\mathrm{S}}$, that includes heat transfer losses at the receiver, is higher for the nonrecuperative case (as commented above, because the lower receiver operating temperatures in the non-recuperative case). But $\eta_{\mathrm{S}}$ is only $6.65 \%$ above for the non-recuperative layout. As global consequence overall thermal efficiency, $\eta$, is, as mentioned above, $28 \%$ better in the recuperative case.

Nevertheless, annual net energy output is similar. It is only $3.54 \%$ above for the recuperative case. These similar values are a consequence of the elected plant operation strategy. It is considered that hybridization is used to keep approximately constant turbine inlet temperature,
Gas Turbine Unit

- Combustion Chamber

- Recuperator

Turbine

Auxiliary 
Table 4

Main parameters and indicators of the plant both for the recuperative and for the non-recuperative configurations in Seville (SOLUGAS location). Specific $\mathrm{CO}_{2}$ emissions, net energy, overall thermal efficiency $(\eta)$, heliostats field efficiency $\left(\eta_{0}\right)$, and solar share $(f)$ calculated in annual values. Relative deviations refer to the non-recuperative case with respect to the recuperative one.

\begin{tabular}{cccc}
\hline Parameter & Recuperative & $\begin{array}{c}\text { Non- } \\
\text { recuperative }\end{array}$ & $\begin{array}{c}\text { Deviation } \\
(\%)\end{array}$ \\
\hline LCoE (USD/MWh) & 158.1 & 184.7 & 16.8 \\
Capital cost (Million USD) & 30.74 & 30.49 & -0.81 \\
Annual fuel consumption (10 ${ }^{3}$ & 7.31 & 10.24 & 40.05 \\
ton/year) & & & \\
Specific CO $\mathrm{CO}_{2}$ emissions (kg/ & 453.1 & 657.8 & 45.18 \\
MWh) & & & \\
$\mathrm{E}_{\mathrm{net}}(\mathrm{GWh} /$ year) & 39.94 & 38.53 & -3.54 \\
$\eta_{\mathrm{H}}$ & 0.392 & 0.277 & -29.30 \\
$\eta_{0}$ & 0.658 & 0.658 & - \\
$\eta_{\mathrm{S}}$ & 0.276 & 0.294 & 6.65 \\
$\eta$ & 0.349 & 0.252 & -27.96 \\
$f$ & 0.202 & 0.151 & -25.19 \\
\hline
\end{tabular}

developed from the commercial point of view can always have some uncertainty. Nevertheless, the comparison between numerical values calculated within the same scheme at different conditions is interesting. In this section, the aim is to compare LCoE values at two locations of Spain with different climatological conditions: globally similar direct normal irradiance (DNI) annual records but quite different average ambient temperatures.

In the previous computations, the location of the SOLUGAS project was elected. Seville is a well-known location for thermosolar installations because of its good solar records. It is at the south of Spain at a latitude $37.4^{\circ} \mathrm{N}$. Annual DNI is about $1975 \mathrm{kWh} / \mathrm{m}^{2}$. Peak values of DNI above $800 \mathrm{~W} / \mathrm{m}^{2}$ are usual at any season. Weather is mediterranean: dry and warm, with many sunny days at any season. Rain is concentrated in winter (approximately 50 rainy days per year), and temperatures are quite hot in summer and warm in winter. Yearly average is about $18.6^{\circ} \mathrm{C}$. Altitude above sea level is small, below $10 \mathrm{~m}$ in several sites.

It was chosen another location about $500 \mathrm{~km}$ to the north of Seville to compare with, Salamanca. Latitude is $40.4^{\circ} \mathrm{N}$. But altitude is quite different (it is located on a plateau about $800 \mathrm{~m}$ above see level) and so, climatological conditions. DNI is slightly below Seville, but values are acceptable, around $1834 \mathrm{kWh} / \mathrm{m}^{2}$. Weather is continental and dry. There are only about 64 days per year with more than $1 \mathrm{~mm}$ rainfall. But, probably, the most important difference comparing with Seville is ambient temperature. Summers are warm and winters cold, in such a way that yearly averaged temperature is $12.1{ }^{\circ} \mathrm{C}$ (about six degrees below Seville). Our main interest in the comparison between these two locations is to check the influence of this difference in temperature. $A$ priori, lower temperatures should favor the increase of the thermal efficiency of the power unit, but also would affect the heat transfer losses at the receiver.

Table 5 contains the data for the two locations. Globally, records are quite similar for both sites. Solar share is higher in Seville, about $13 \%$. Heliostat field efficiency is similar, but slightly above for Salamanca. Power unit efficiency, $\eta_{\mathrm{H}}$ is $1.54 \%$ above for Salamanca because average ambient temperature is lower. The largest difference comes from $\eta_{\mathrm{S}}$. It is $4.56 \%$ larger at Seville. Probably this is due to the larger mean ambient temperature, that provokes a lower temperature gradient between the solar receiver and its surroundings, so lower heat transfer losses. Overall efficiency is about $2.01 \%$ larger in Salamanca. This is likely due to two facts: on one hand, thermodynamic cycle efficiency is larger in Salamanca because mean ambient temperature is smaller. On the other hand, solar share in Salamanca is lower, so the plant is working on pure combustion mode during more time and this operation is always associated to larger overall efficiency because the solar subsystem (and the corresponding loss) is disconnected.
Table 5

Thermodynamic and thermo-economic indicators at two different locations in Spain with quite different climatological conditions, Seville and Salamanca. Relative deviations are calculated for Salamanca with respect to Seville.

\begin{tabular}{cccc}
\hline Parameter & Seville & Salamanca & Deviation (\%) \\
\hline LCoE (USD/MWh) & 158.1 & 163.7 & 3.512 \\
Capital cost (Million USD) & 30.74 & 30.67 & -0.24 \\
Annual fuel consumption (10 ${ }^{3}$ ton/year) & 7.31 & 6.89 & -5.83 \\
Specific CO $\mathrm{CO}_{2}$ emissions (kg/MWh) & 453.1 & 450.8 & -0.51 \\
$\mathrm{E}_{\text {net }}(\mathrm{GWh} /$ year) & 39.94 & 37.80 & -5.36 \\
$\eta_{\mathrm{H}}$ & 0.392 & 0.398 & 1.54 \\
$\eta_{0}$ & 0.658 & 0.660 & 0.24 \\
$\eta_{\mathrm{S}}$ & 0.276 & 0.263 & -4.56 \\
$\eta$ & 0.349 & 0.356 & 2.01 \\
$f$ & 0.202 & 0.175 & -13.24 \\
\hline
\end{tabular}

Fuel consumption and, so, emissions are very similar and final LCoE is only $3.5 \%$ worse for Salamanca. It is 163.7 USD/MWh against 158.1 USD/MWh for Seville. There results suggest that locations with higher latitudes than most usual in thermosolar plants, but with acceptable insolation records and relatively low average temperatures deserve to be studied as feasible places for this kind of concentrated solar power plants.

\section{Sensitivity analysis of plant efficiencies and LCoE}

The aim of this section is to analyze how several design inputs affect thermodynamic and thermo-economic output values. One of the key strong points of the developed model is that it allows to survey the main parameters of any of the plant subsystems (power unit, heliostat field, and solar receiver) in a realistic and precise way, but without an excessive computational cost. The next subsections present some interesting results on the analysis performed, but other alike ones could be done.

\subsection{Power unit parameters}

Two essential design parameters of the Brayton-like power unit have been selected for analysis: the compressor pressure ratio, $r_{\mathrm{p}}$, and the turbine inlet temperature, $T_{3}$. Beginning with the pressure ratio, Fig. 5 shows the evolution with $r_{\mathrm{p}}$ of some variables with a thermodynamic meaning. Solar share, $f$ (see Fig. 5(a)) decreases with $r_{\mathrm{p}}$ in the interval displayed because the operating temperature of the solar receiver (and the one reached by the working fluid after the heating from the receiver) decreases in a similar way, and, thus, an increasing amount of fuel is burned when $r_{\mathrm{p}}$ increases to meet the fixed value of $T_{3}$. The net energy obtained per year, $E_{\text {net }}$, behaves as the power output with the pressure ratio. It increases from small $r_{\mathrm{p}}$, reaches a maximum about $r_{\mathrm{p}} \simeq 11$ and decreases again. Pressure ratio, in our scheme, affects the plant overall thermal efficiency, $\eta$, through the heat engine efficiency, $\eta_{\mathrm{H}}$. It was shown in previous works that, for a system with similar dimensions as the one considered here, $\eta_{\mathrm{H}}$ displays a maximum for pressure ratios about 4-6, and then decreases almost linearly for higher pressure ratios [26]. This is displayed in overall efficiency, $\eta$, as shown in Fig. 5(c). In all the plots of this figure and the following ones, the red dot refers to the SOLUGAS project design point.

The behavior of capital costs, fuel consumption, and LCoE with $r_{\mathrm{p}}$ is shown in Fig. 6. Capital costs increase in a parabolic shape with $r_{\mathrm{p}}$ because, both, compressor and turbine costs increase in a similar way. With the correlations considered in this work [40], in the pressure ratio interval between 6 and 12, compressor costs increase from $6.0 \times 10^{5}$ USD dollars to $9.5 \times 10^{5}$ (that is about $58 \%$ of relative increment) and turbine costs increase is similar. This is reflected in whole capital costs as an increment about 3\%. Fuel consumption along a year (see Fig. 6(b)) increases about 1000 ton with the corresponding increase in OML costs. 

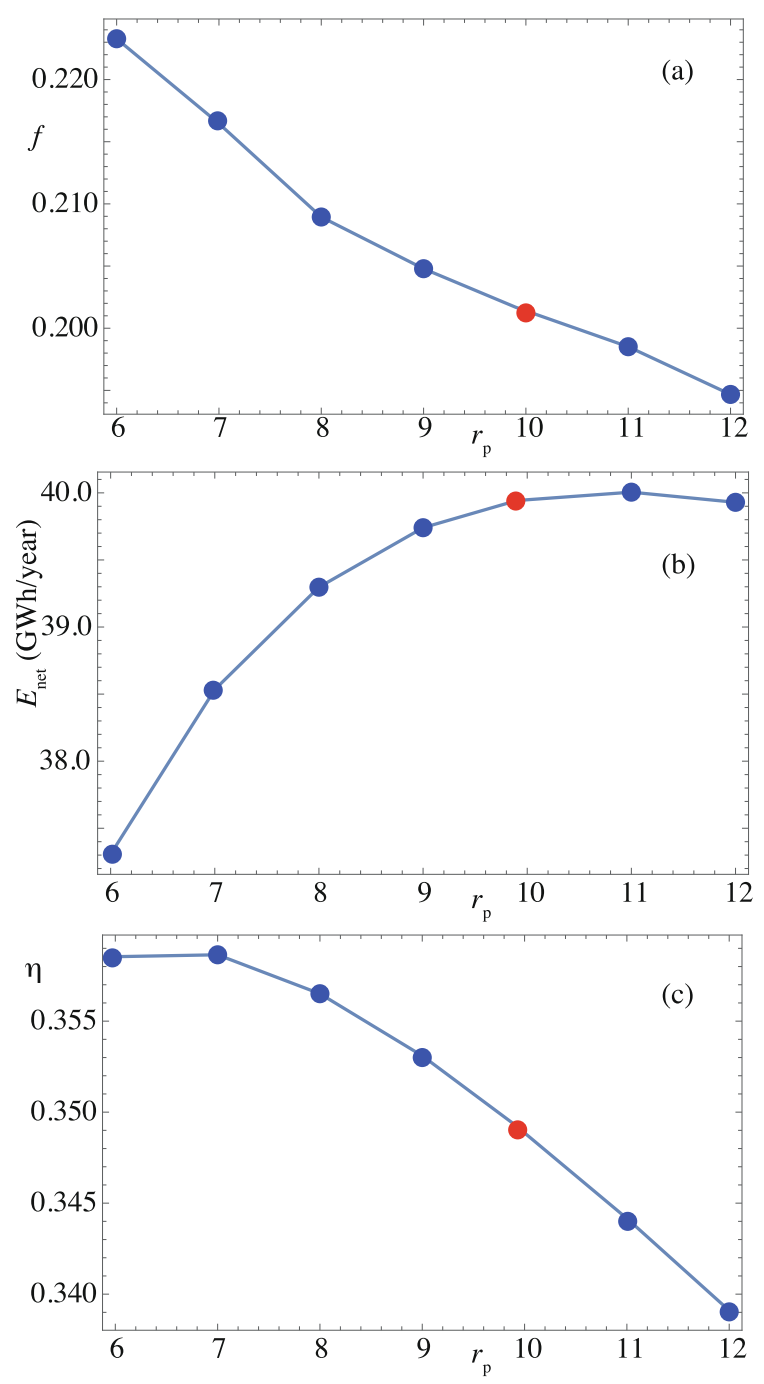

Fig. 5. Evolution of some thermodynamic parameters with the pressure ratio of the compressor in the power unit: (a) $f$, solar share; (b) $E_{\text {net }}$, net energy produced in a year; and (c) $\eta$, overall plant thermal efficiency. The red dot corresponds to the design point of SOLUGAS project [21].

This increase is due to the decrease of solar share as commented in the paragraph before.

LCoE behavior is plotted against $r_{\mathrm{p}}$ in Fig. 6(c). It has a parabolic shape and displays a minimum about $r_{\mathrm{p}} \simeq 9$, i.e., at slightly higher values that the maximum displayed by the plant overall efficiency, $\eta$. This evolution is a consequence that LCoE is the ratio between costs and net annual energy produced. The numerator (capital and OML costs) increases with $r_{\mathrm{p}}$ (see Fig. 6(a)), and also $E_{\text {net }}$ increases, but at a different rate as shown in Fig. 5(b). Consequently, LCoE displays a minimum in the surveyed interval. However, although the existence of a minimum is qualitatively interesting, the numerical variation of LCoE in the considered pressure ratio interval is not large. Difference among minimum value and the highest in the interval is about 4.0 USD/MWh ( $2 \%$ in relative terms).

Another essential factor at the design level of any gas turbine power unit is the turbine inlet temperature, $T_{3}$. Larger values of $T_{3}$ ensure better thermodynamic efficiencies on the power unit cycle, but also increase production costs of the turbine components because very specific alloys or ceramic coatings are required to withstand high temperatures. Thus, it has both consequences, purely thermodynamic and also economic. Fig. 7 shows the rapid increase of overall efficiency with larger $T_{3}$ values. The relative increase in the temperatures interval
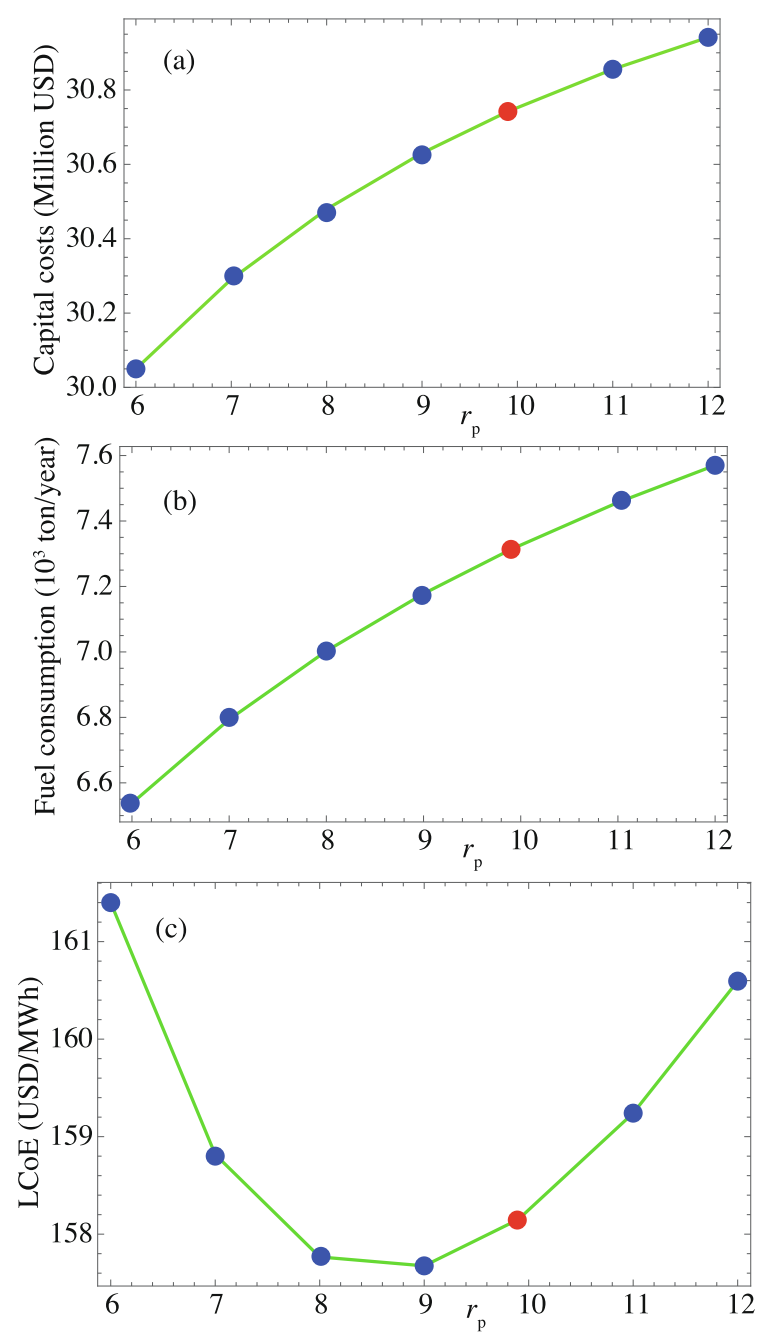

Fig. 6. Evolution with the pressure ratio of the compressor in the power unit of: (a), total investment capital costs; (b), fuel consumption; and (c), LCoE.

$[1300,1500]$ is about $20 \%$. Nevertheless, the increase in $T_{3}$ also provokes an increase in net power output and so, in the net annual energy, which increases $37.5 \%$ in the interval (see Fig. 7(b)). Solar share decreases because as $T_{3}$ increases more fuel is needed to reach the required temperature.

Gas turbine costs rapidly increase for temperatures above $1400 \mathrm{~K}$ approximately. This is depicted in Fig. 8(a). The evolution of the gas turbine costs with temperature was taken from [40]. Fuel consumption linearly increases with $T_{3}$. To have an approximate numerical reference, it increases from 6400 to 7800 ton/year in the basis of natural gas. As a consequence of the balance between increasing investment and OML costs on one hand and net yearly energy production on the other hand, LCoE presents an almost linear decrease with increasing $T_{3}$, i.e., net energy production increases more rapidly than costs, which is an interesting conclusion. Particularly, the lowest LCoE is got at $1500 \mathrm{~K}$ and is $148 \mathrm{USD} / \mathrm{MWh}$. The highest is reached at $T_{3}=1300 \mathrm{~K}$ and is about 188 USD/MWh, which is $27 \%$ higher.

The sensitivity of overall plant efficiency and LCoE to simultaneous changes in $r_{\mathrm{p}}$ and $T_{3}$ has been also studied. Fig. 9 shows these analyses as density plots. Larger thermal efficiencies are observed as turbine inlet temperature increases and pressure ratio decreases (left panel of Fig. 9). In the considered intervals, $\eta$ reaches its largest values for temperatures above $1450 \mathrm{~K}$ and $r_{\mathrm{p}}$ between 6 and 8 . Nevertheless, as temperature increases LCoE is almost independent of the pressure ratio, which is a significant result. In other words, for high temperatures, pressure ratio is 

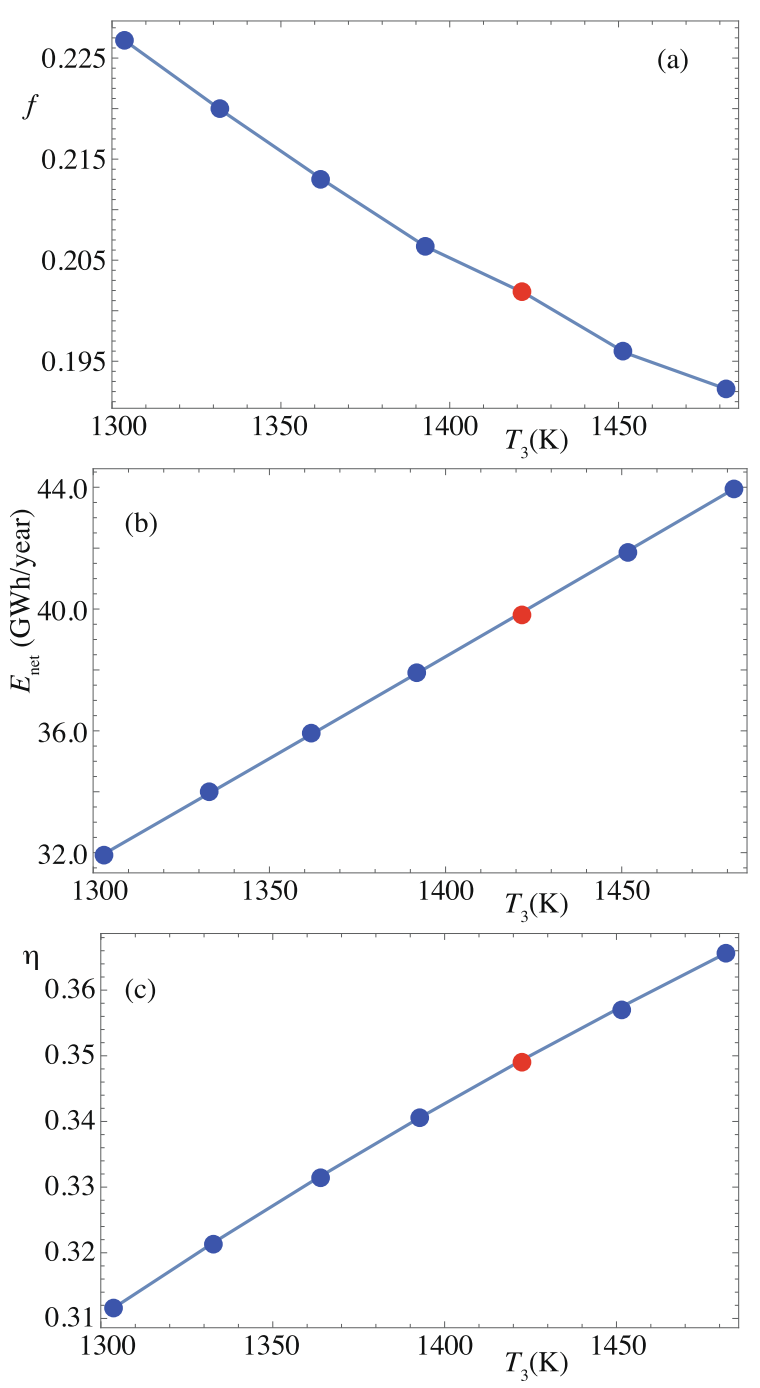

Fig. 7. Evolution of some thermodynamic parameters with the turbine inlet temperature, $T_{3}$ : (a) $f$, solar share; (b) $E_{\text {net }}$, net energy produced in a year; and (c) $\eta$, overall plant thermal efficiency. The red dot corresponds to the design point of SOLUGAS project [21]. (For interpretation of the references to colour in this figure legend, the reader is referred to the web version of this article.)

not a critical variable to minimize LCoE values. For temperatures above $1400 \mathrm{~K}, \mathrm{LCoE}$ values around $150 \mathrm{USD} / \mathrm{MWh}$ are got for whichever value of $r_{\mathrm{p}}$ (see right panel of Fig. 9).

\subsection{Heliostat field parameters}

The sensitivity of main efficiencies (thermal and optical) and economical parameters (investment costs, OML costs, and LCoE) as functions of several key parameters of the heliostat field has been surveyed. Parameters have been checked one by one. In the following paragraphs the main conclusions are condensed:

- Mirrors area, $A H$. Starting from the design point mirror area of SOLUGAS project, $A H=121.3 \mathrm{~m}^{2}$, an interval $[110,130] \mathrm{m}^{2}$ has been surveyed (considering square mirrors). In this interval mean optical efficiency of the field linearly decreases with larger mirrors areas. For $A H=110 \mathrm{~m}^{2}, \eta_{0}=0.661$ and for $A H=130 \mathrm{~m}^{2}, \eta_{0}=$ 0.655 , which corresponds to a decrease of $0.92 \%$. It was checked that this decrease is associated with a reduction in all the main factors of the field optical efficiency: $\cos \omega$, spillage, and attenuation. This is reflected in plant overall efficiency in a decrease of about
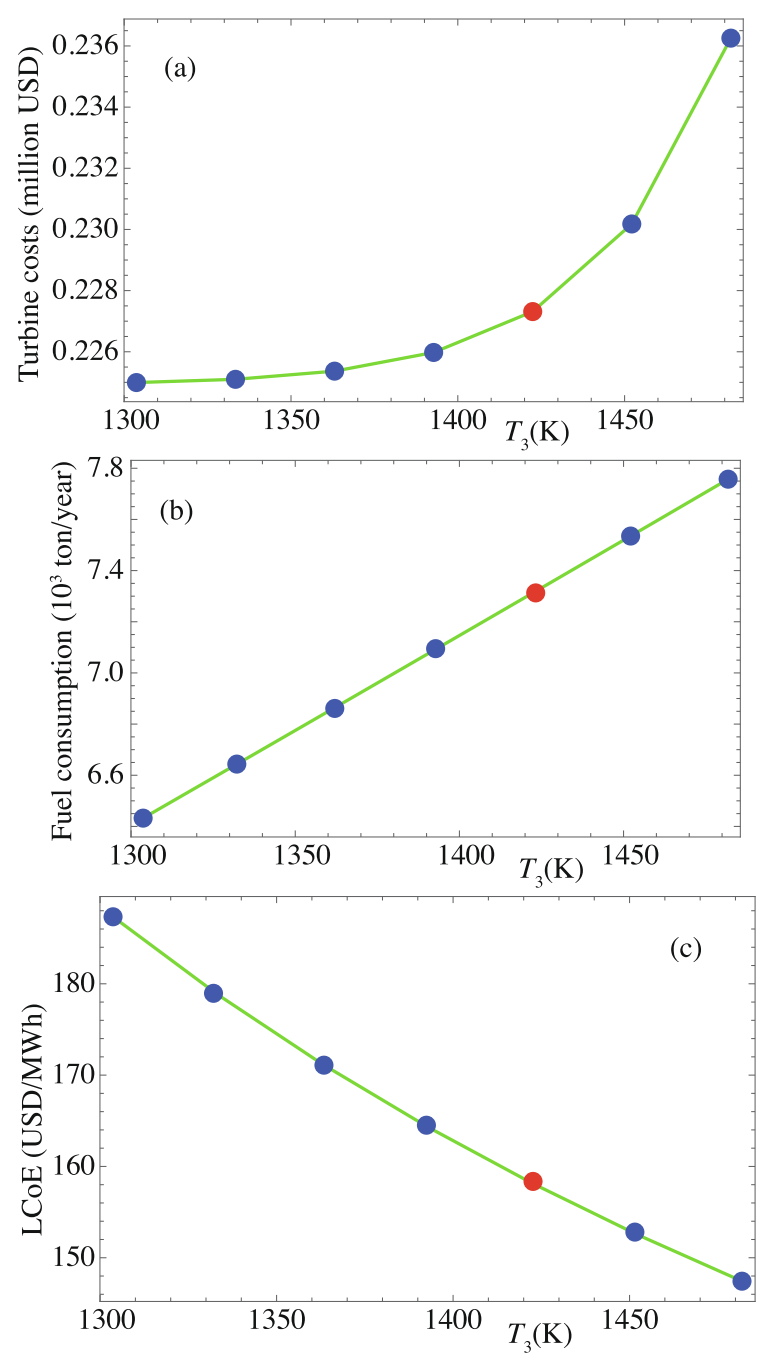

Fig. 8. Evolution with the turbine inlet temperature, $T_{3}$ of: (a), gas turbine costs; (b), fuel consumption; and (c), LCoE.

1.15\%. Moreover, heliostat units costs increase with $\mathrm{AH}$ and consequently LCoE increases from 157.30 to 158.80 , as it is displayed in Fig. 10(a). This corresponds to an increase in LCoE of about $0.95 \%$.

- Safety distance between adjacent heliostats, DS. At design point, this required safety distance is taken as 0.3 in units given by mirrors length, $L H$ (see Table 1 ). An interval $[0,1]$ has been studied. As this distance is increased, $\eta_{0}$ and $\eta$ monotonically decrease and, at the same time, field costs increase, provoking an slight increase of LCoE. In the limit case $D S=0$, LCoE would eventually be $157.5 \mathrm{USD} / \mathrm{MWh}$ and at the other side, for $D S=1$ it would be 159.3 USD/MWh. This increase is about 1.14 in percentile terms.

- Blocking and shadowing factors, $f_{\mathrm{b}} \cdot f_{\mathrm{sh}}$. As the developed model considers both factors independent of each mirror, they have been analyzed together. Design point value is $f_{\mathrm{b}} \cdot f_{\mathrm{sh}}=0.95$ and the investigated interval is $[0.93,0.97]$. Of course, optical efficiency grows with the increase of this factor. For $f_{\mathrm{b}} \cdot f_{\mathrm{sh}}=0.95, \eta_{0}=0.644$ and for $f_{\mathrm{b}} \cdot f_{\mathrm{sh}}=0.97$ it is 0.672 . This represents a gain of $3.35 \%$ that leads to a much smaller increase of overall efficiency, $0.30 \%$. LCoE drops when blocking and shadowing losses decrease, but in numerical terms, the decrease is small, $0.16 \%$. This fall is shown in Fig. 10(b).

- Reflectivity, $\rho$. It plays the same role that blocking and shadowing factors, appears in the optical efficiency, $\eta_{0}$, as a multiplicative factor. For design point, it was assumed to be $\rho=0.836$ and a wide realistic interval $[0.818,0.854]$ is analyzed. When $\rho$ is covered in this 

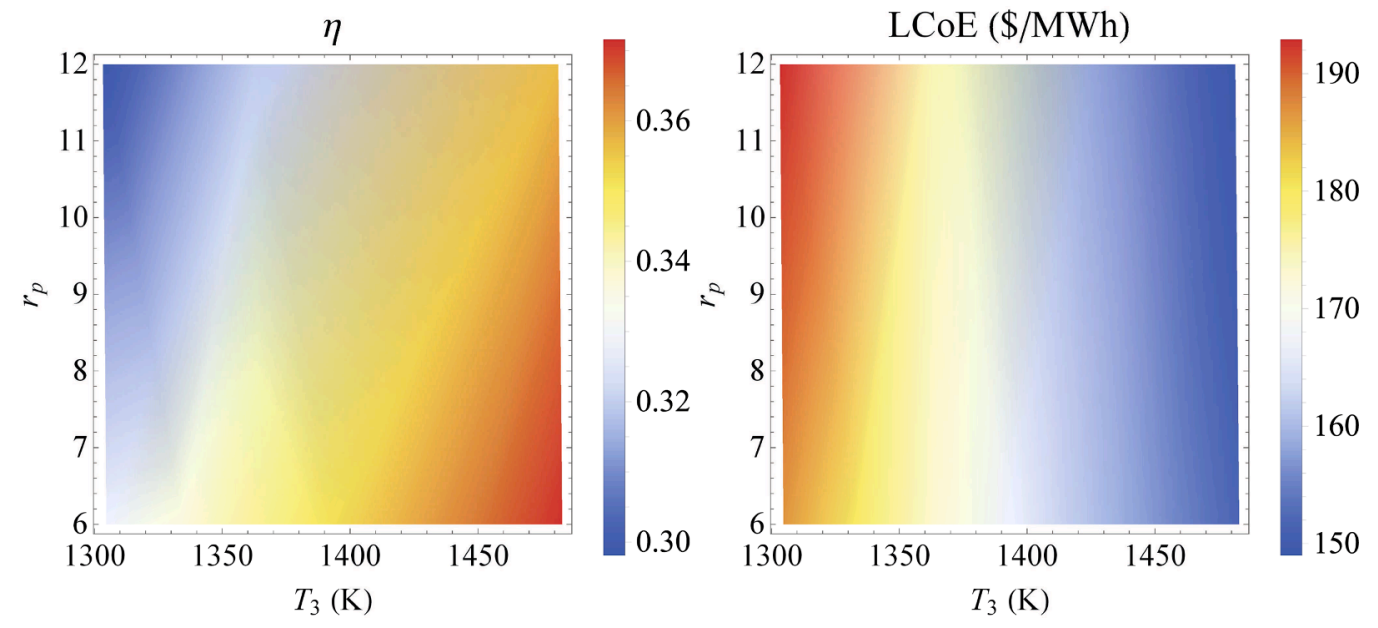

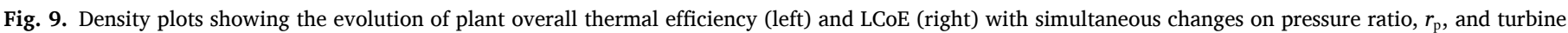
inlet temperature, $T_{3}$.
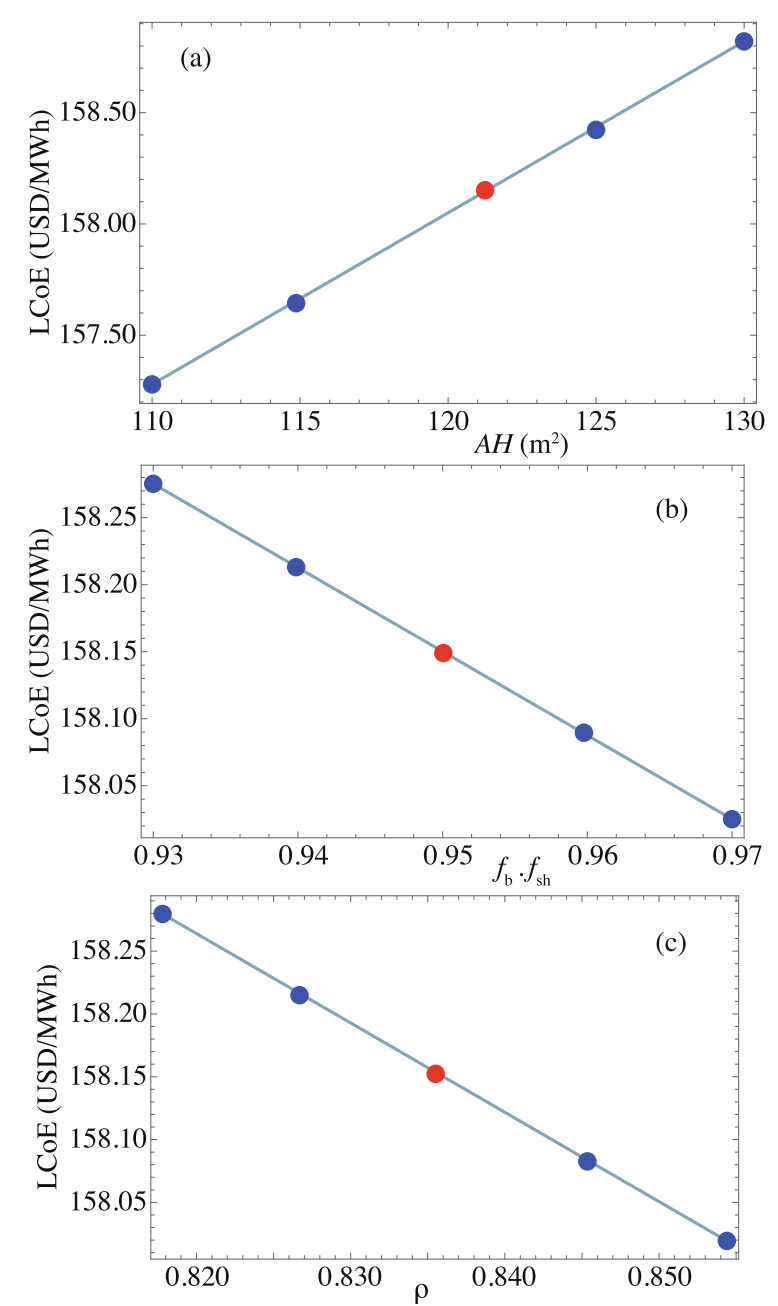

Fig. 10. LCoE sensitivity to some key parameters of the heliostat field: (a), $A H$, mirrors area; $f_{\mathrm{b}} \cdot f_{\mathrm{sh}}$, blocking and shadowing efficiency factor; and (c), $\rho$, mirrors reflectivity. The red dot corresponds to SOLUGAS design point [21]. (For interpretation of the references to colour in this figure legend, the reader is referred to the web version of this article.) interval, $\eta_{0}$ increases from 0.643 to 0.673 , and correspondingly overall efficiency grows up from 0.349 to 0.350 , i.e., $\eta$ increases $0.31 \%$. LCoE (see Fig. 10(c)) decreases $0.16 \%$. This numerical decrease is almost identical to the one associated with a reduction in blocking and shadowing losses and would represent the margin of improvement in LCoE with respect to an improvement on mirrors surface reflection of solar energy towards the receiver.

- First row distance to the tower, $R_{\min }$. This is the minimum distance from the first heliostats in the field to the central tower. It is also a main parameter in the design of any heliostat field. SOLUGAS field takes $R_{\min }=64 \mathrm{~m}$. Our model has been applied to study a wide interval $[35,75] \mathrm{m}$. Optical and overall efficiencies decrease with increasing $R_{\min }$, but numerical differences are small. Moreover, land area and so, land investment costs increase with $R_{\min }$. The whole consequence is that LCoE increases, about $0.18 \%$ in the considered interval.

- Finally, the tower height, THT is analyzed. It is a key parameter in which respect to investment costs and solar subsystem efficiencies. Design point value is $T H T=65 \mathrm{~m}$ and the interval considered for analysis 45-75 m. Results for some indicators are shown in Fig. 11. From the figure is clear that THTprovokes an increase of efficiencies (optical and thermal), but also capital costs are larger because of tower costs. In the analyzed interval tower costs grow from 3.25 to 4.25 Million USD. This is a substantial increase of about $30.77 \%$. Nevertheless, it is partially subsumed by the gain in thermal efficiency and LCoE is not so sensitive to changes in THT. It increases in that interval from about 156.0 to $159.5 \mathrm{USD} / \mathrm{MWh}$, that is $2.24 \%$. It is also noticeable that the behavior of all output parameters with respect to THT is monotonic (slightly parabolic), there are neither maxima nor minima.

\subsection{Solar receiver main parameters}

This subsection is devoted to analyze the role played by the basic solar receiver parameters in final overall plant outputs and LCoE. Next, the main conclusions of the analysis are enumerated.

- Receiver emissivity, $\alpha$. The global emissivity of the receiver accounts for the heat transfer losses associated with radiation as shown in Eq. (10). Larger values of $\alpha$ provoke larger radiation losses, and thus, smaller solar subsystem efficiency, $\eta_{\mathrm{S}}$, and smaller overall efficiency, $\eta$. Sensitivity of efficiencies and LCoE were surveyed in a realistic interval around design point value, that is $\alpha=0.10$. The interval chosen was $[0.05,0.30]$. As $\alpha$ increases, radiation losses do, and so, overall plant efficiency decreases and LCoE increases. All the curves 

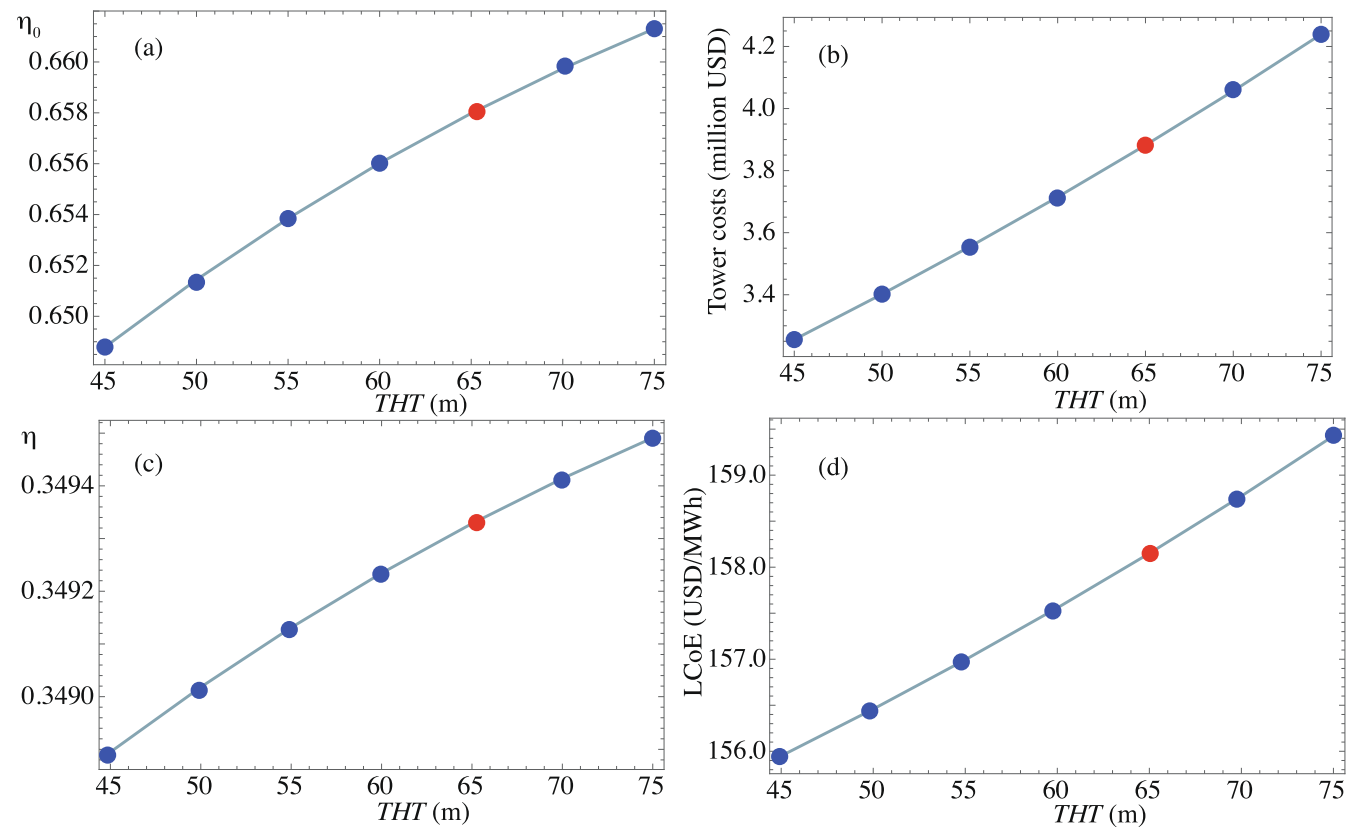

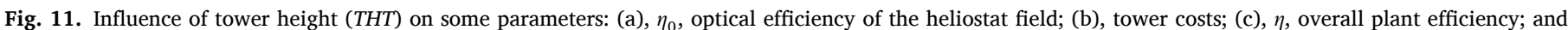
(d) LCoE.

are approximately linear, as, for example LCoE, depicted in Fig. 12 (a). In numerical terms, sensitivity of $\eta$ and LCoE is small. In the referred interval $\eta$ decreases from 0.350 to 0.348 , that is only $0.01 \%$. LCoE increase in that interval is larger, about $0.33 \%$. As limit case, for an hypothetical perfect cavity receiver from the viewpoint of radiation losses, $\alpha \simeq 0$, LCoE would decrease to $157.94 \mathrm{USD} / \mathrm{MWh}$. As design point LCoE is 158.15 USD/MWh, this eventual decrease could amount at best $0.13 \%$.

- Effective conduction and convection heat transfer coefficient, $\bar{U}_{\mathrm{L}}$. This coefficient plays an identical role as $\alpha$ for effective conduction and convection heat transfer losses. Its limit $\bar{U}_{\mathrm{L}} \rightarrow 0$ would correspond to a receiver without heat transfer losses through the tower itself to the ground, nor through the surrounding air. The interval analyzed is $[3.0,7.0] \mathrm{W} /\left(\mathrm{m}^{2} \mathrm{~K}\right.$ ) (at the design point, $\bar{U}_{\mathrm{L}}=5 \mathrm{~W} /\left(\mathrm{m}^{2} \mathrm{~K}\right)$ ). The increase of LCoE with $\bar{U}_{\mathrm{L}}$ is linear (see Fig. 12(b)). The relative increase in the surveyed interval is around $0.063 \%$. Total elimination of these losses, as limit speculative case, would lead to an LCoE about 158.025 USD/MWh.

- Effectiveness of the receiver as heat exchanger, $\varepsilon_{\mathrm{HS}}$. This coefficient measures the ratio between the solar heat input in the receiver (once heat transfer losses has been discounted) and the solar heat input in the working fluid performing the thermodynamic cycle. It depends on the heat transfer materials properties, size, and geometry (for instance of the ceramic sponge at the back of the receiver for high temperature receivers). The limit case $\varepsilon_{\mathrm{HS}} \rightarrow 1$ would represent an ideal heat exchange. A realistic interval to analyze the weight of this parameter is $[0.68,0.88]$. As $\varepsilon_{\mathrm{HS}}$ increases, overall efficiency increases (from 0.346 to 0.353 ) and LCoE decreases (from 158.9 to 157.4 USD/ $\mathrm{MWh}$ ). In the case of an ideal heat transfer from the receiver to the fluid, LCoE could decrease to 156.5 USD/MWh, i.e., from the design point $\left(\varepsilon_{\mathrm{HS}}=0.78\right)$ LCoE could decrease as best $1.28 \%$.

- Solar receiver aperture diameter, $D R$. This parameter is essential because influences the plant efficiencies and thermo-economic records at several levels. SOLUGAS project makes use of a cavity receiver with a diameter of $5 \mathrm{~m}$. An analysis of a wide interval [3.0, $7.0] \mathrm{m}$ has been performed in order to get into its influence from both qualitative and quantitative perspectives. Fig. 13 displays the evolution of some efficiencies with $D R$. It slightly affects the factor $\cos \omega$.
As seen in the figure, $\cos \omega$ decreases as $D R$ increases. It does in a linear way, but with relatively low numerical differences. Nevertheless, spillage factor, $f_{\mathrm{sp}}$, is greatly associated with $D R$. As $D R$ increases, $f_{\mathrm{sp}}$ approaches $f_{\mathrm{sp}} \simeq 1$ (see Fig. 13(b)). For values of $D R$ around $D R \simeq 7$ this is accomplished, i.e., spillage losses almost disappear. In consequence, the field optical efficiency, $\eta_{0}$, resembles the behavior of $f_{\mathrm{sp}}$ with respect to $D R$ (see Fig. 13(c)). In the span considered, $\eta_{0}$ increases from 0.60 to 0.66 , which is a noteworthy numerical increment, about $10 \%$. Moreover, the thermal efficiency of the whole solar subsystem, $\eta_{\mathrm{S}}$, apart from depending on $D R$ through $\eta_{0}$ it also depends on the concentration ratio, $C$, and so, on $D R$, in the heat transfer losses term (see Eq. (10)). As $D R$ increases, heat transfer losses also increase. Thus, the balance between optical losses and heat transfer losses makes that $\eta_{\mathrm{S}}$ has a maximum as displayed in Fig. 13(d). For the reference plant considered, maximum $\eta_{\mathrm{S}}$ is achieved at $D R \simeq 4$, and is about 0.28 .

From the thermo-economic viewpoint, receiver size and design particularities have a deep impact. Its cost has a large degree of uncertainty, specially in the case of high temperature cavity receivers as the case considered here. Up-to-date receiver designs are non-standard prototypes, designed for particular projects, mass production seems still distant. As suggested by Augsburger [46], in this work receiver costs are estimated from a reference base case as a function of receiver area, progress ratio, and price index. The evolution with $D R$ of receiver costs is shown in Fig. 14(a). Evolution is linear and the slope is very high, about 1.3 Million USD/m. This means that in the interval considered for $D R$, receiver cost increases $157.6 \%$. This is reflected in total capital costs as an increase from 27.2 to 34.2 Million USD, which in porcentual terms represents about $25.7 \%$. The dependence of fuel consumption and net annual energy with $D R$ are represented in Figs. 14(b) and (c). Net yearly energy presents a maximum about $D R \simeq 4$ and fuel consumption a minimum about the same value. Both evolutions are due to the behavior of the thermal solar subsystem efficiency, $\eta_{\mathrm{S}}$ (see Fig. 13 (d)), as commented before. Thus, LCoE evolves as displayed in Fig. 14(d). It rapidly increases with $D R$, in an almost quasilinear way. No relative maximum or minimum are found. This is because the linear increase in costs is more important than the parabolic behavior of net energy or OML costs associated with fuel consumption. The 

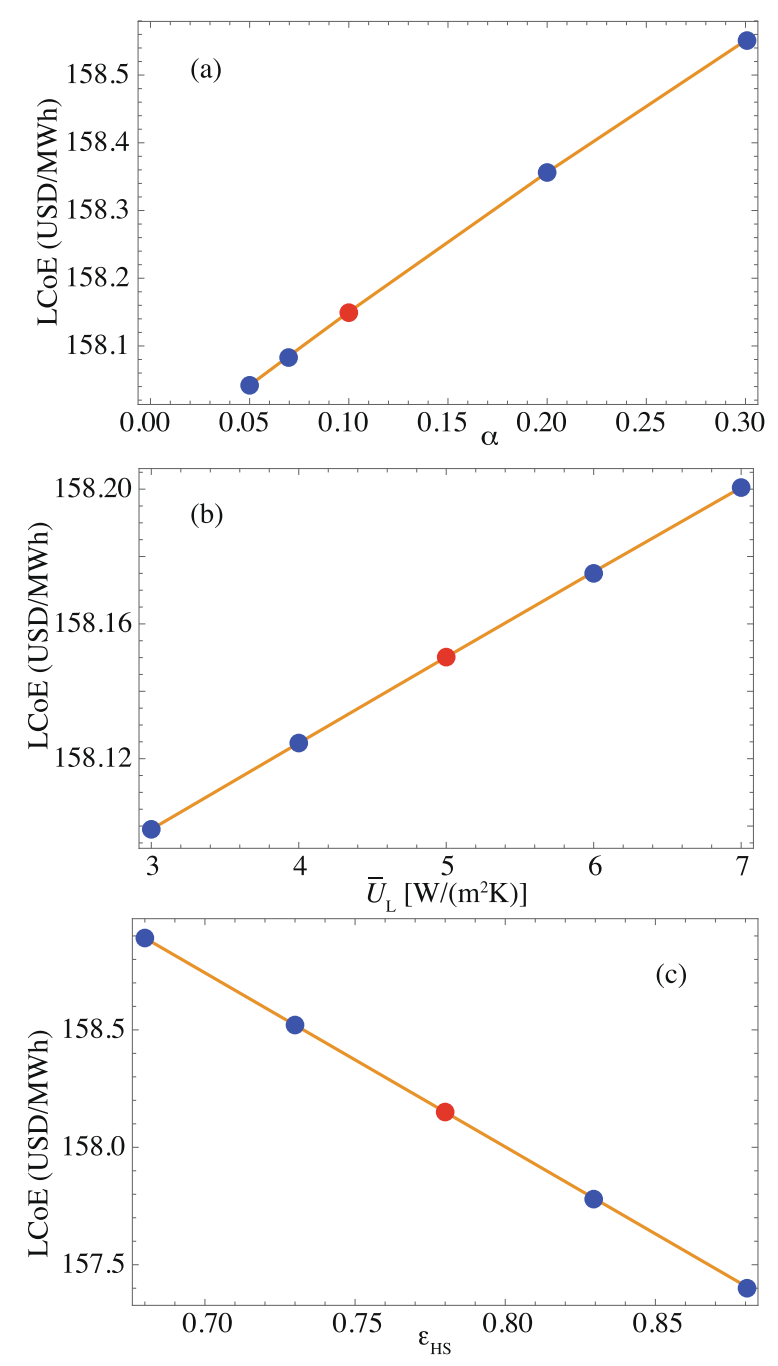

Fig. 12. LCoE dependence on some receiver parameters: (a), $\alpha$, receiver emissivity; (b), $\bar{U}_{\mathrm{L}}$, effective conduction-convection heat transfer coefficient; and (c), $\varepsilon_{\mathrm{HS}}$, receiver effectiveness as heat exchanger.

slope of the increase of LCoE with $D R$ is about 5.75 USD/(MWh.m). This represents an increase of LCoE in the interval from $D R=3$ to $D R=7$ of about $15.6 \%$, which is really noticeable.

\section{Discussion}

The model developed in this work is focused to perform a thermoeconomic analysis of a hybrid Brayton central tower thermosolar plant. It includes the following ingredients. A detailed design and description of the solar field which incorporates optical efficiency terms depending on each heliostat as $\cos \omega$ factor, spillage, and attenuation, and other taken as independent as blocking, shadowing, and reflectivity. The assumption of the last ones as constant allows to speed up numerical calculations and does not affect final conclusions for the whole plant. For the solar receiver, a simple scheme valid for cavity receivers operating at high temperatures is assumed. Heat transfer losses coming from radiation, conduction, and convection are considered. The power unit is supposed to operate as a closed Brayton-like thermodynamic cycle that includes the most significant losses in these systems. The connection between solar receiver and the thermodynamic cycle is associated with a non-ideal heat exchanger.

For numerical implementation and analysis, a prototype plant at a pre-commercial scale (about $5 \mathrm{MWe}$ ) was considered, the SOLUGAS project developed at the south of Spain. Heliostat field and gas turbine parameters, and thermo-economic correlation were adapted to get closer to that prototype plant. Considering a recuperative gas turbine power unit, thermal overall plant efficiency is predicted to be about 0.349 . Solar share is relatively low because of the undersized heliostat field due to the pioneer essence of SOLUGAS project. This means that the combustion chamber burning natural gas is required most of the time in order to ensure that the air flow rate developing the thermal cycle reaches the pre-fixed turbine inlet temperature. Resulting specific $\mathrm{CO}_{2}$ emissions are about $453.1 \mathrm{~kg} / \mathrm{MWh}$. Estimated LCoE in these conditions is $158.1 \mathrm{USD} / \mathrm{MWh}$. It was compared with several referenced values in the literature, for systems alike, but also for different solar technologies, and the predicted values are perfectly in accordance with them. It was checked a plant design eliminating recuperation in the gas turbine. Overall efficiency decreases about $28 \%$ and LCoE increases $16.8 \%$. The main advantage of a non-recuperated layout is that the average operating temperature of the solar receiver is quite lower, and so the efficiency of the solar subsystem (field and receiver) is slightly larger than in the recuperated case.

Another issue was analyzed, the possibility to locate a similar plant at a northern latitude (about $450 \mathrm{kms}$ to the north of the original location of SOLUGAS, Seville, Spain) with not bad solar conditions and average temperatures about six degrees below Seville. The conclusion is that yearly averaged thermal efficiency is larger (about $2 \%$ ), nevertheless LCoE increases about $3.5 \%$. In any case, differences are not so large and probably detailed thermo-economic analysis at those latitudes (and depending of particular climatological conditions) could be interesting.

\section{Conclusions}

In this work it was intended to highlight the importance of global models at the design stage of concentrated solar power plants, particularly in the case of central tower heliostat fields combined with a hybrid gas turbine power unit. These models should include the main particularities of each subsystem (heliostat field, solar receiver, power unit, and heat exchangers) and their interdependence. At a pre-design stage, an overall plant description, depending on a reduced parametrical modeling, is essential in order to achieve the required design or operation objectives. Once the main plant parameters are set, an specific analysis of each subsystem would be demanded in order to guarantee the stated requirements.

The model developed is specially adequate to fulfill a sensitivity analysis of plant outputs with respect to the main variables of any subsystem. This allows to perform a reduction in system dimensionality and to put the focus on those critical design variables. Next, main conclusion of the analysis are summarized:

- The evolution of thermal overall plant efficiency, $\eta$, and LCoE with the pressure ratio of the compressor in the power unit is not linear: $\eta$ shows a maximum at low pressure ratios and LCoE a minimum for slightly larger values. This means that this variable is susceptible of optimization for pre-design, nevertheless numerical changes on those objective functions are not large.

- The turbine inlet temperature is a key parameter in plant costs and operation. An interval of inlet temperatures from 1300 to $1500 \mathrm{~K}$ was surveyed. Capital investment costs greatly increase in that interval, but net annual energy also does, even more rapidly. Thus, LCoE decreases in that temperature span, from 188 to 150 USD/MWh. This is a noticeable reduction, so turbine inlet temperature would be a crucial parameter in plant design.

- Several parameters relative to the heliostat field were analyzed: mirrors area, security distance between them, first region distance to the tower, shadowing and blocking factors, reflectivity, and tower height, THT. The one with a larger weight in plant outputs is tower height. Optical field efficiency and thermal overall plant efficiency increase with THT. But investment costs associated with tower 

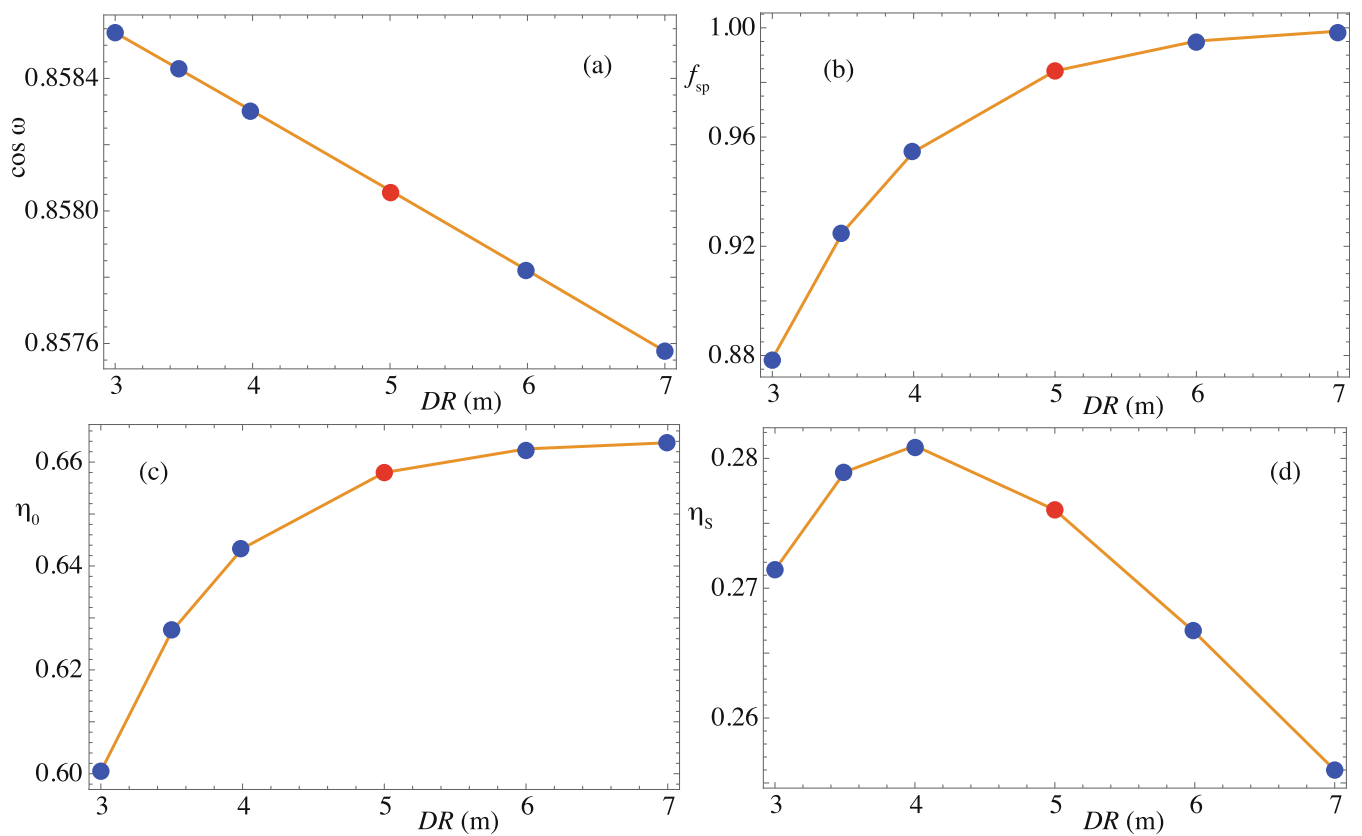

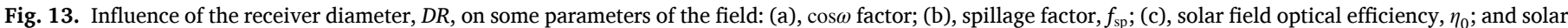
subsystem efficiency, $\eta_{\mathrm{S}}$ (field and receiver).
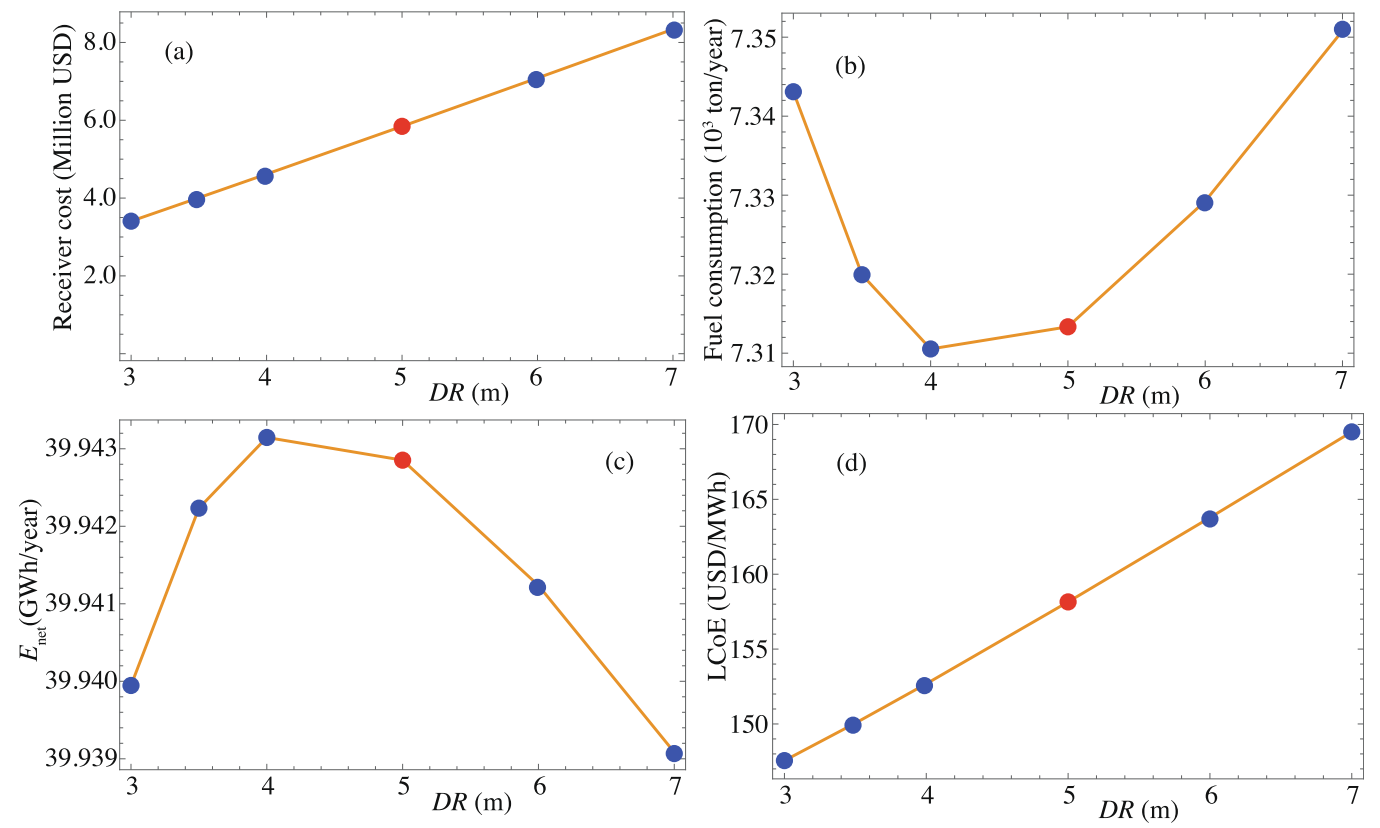

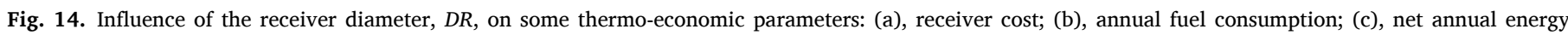
production; (d), and LCoE.

construction also increase, actually faster. Thus, LCoE monotonically increases in the surveyed interval.

- With respect to the receiver, variations on the following parameters were studied: emissivity, conduction-convection effective heat transfer coefficient, heat exchanger effectiveness, and aperture diameter. All of them, except aperture diameter, lead to monotonic evolutions for efficiencies or economic parameters. Moreover, their influence in final plant numerical values is relatively small. Nevertheless, the influence of receiver aperture diameter is essential. As it increases, spillage factor does and so, field optical efficiency grows up to an asymptotic limit. This provokes a maximum of the solar subsystem global efficiency, but at the same time, investment costs increase with receiver diameter. The increase is so quick that dominates over the other considerations and LCoE linearly increases with the diameter.

All these conclusions allow to point out at least two key variables in order to go on the research and development of plants based on this technology for a future profitability and commercial expansion. First, the capacity to work on higher concentration ratios that allow on one hand higher turbine inlet temperatures and, on the other hand, relatively smaller aperture size for the solar receiver. This is associated with operating gas turbines at very high temperatures, finding the appropriate materials with prices quite lower than nowadays. And also, to 
seek for standardized high temperature solar receivers geometries and materials that also could lead to reduced investment costs. Second, and probably not so significant, to adapt tower height and costs to field and receiver design.

All the findings in this work could be extrapolated for plants with power outputs in an interval close to 10 MWe. Other system scales, as smaller towers operating together with micro gas turbines for distributed energy production (in the scale of tens or a few hundreds of $\mathrm{kWe}$ ), or larger plants about several hundreds of megawatts, should be investigated. Models like the one developed in this paper can be elucidating guides in this research.

\section{Declaration of Competing Interest}

The authors declare that they have no known competing financial interests or personal relationships that could have appeared to influence the work reported in this paper.

\section{Acknowledgements}

Financial support from University of Salamanca, Banco Santander, and Junta de Castilla y León of Spain (project SA017P17) is acknowledged.

\section{References}

[1] G.J. Nathan, M. Jafarian, B.B. Dally, W.L. Saw, P.J. Ashman, E. Hu, A. Steinfeld, Solar thermal hybrids for combustion power plant: A growing opportunity, Prog. Ener. Comb. Sci. 64 (2018) 4-28.

[2] L. Weinstein, J. Loomis, B. Bhatia, D. Bierman, E. Wang, G. Chen, Concentrating solar power, Chem. Rev. 115 (2015) 12797-12838.

[3] S. Relloso, Y. Gutiérrez, SENER molten salt tower technology. ouarzazate NOOR III case, in: AIP Conference Proceedings, Vol. 1850, American Institute of Physics, 2017, p. 030041. doi:10.1063/1.4984384.

[4] O. Olumayegun, M. Wang, G. Kelsall, Closed-cycle gas turbine for power generation: a state-of-the-art review, Fuel 180 (2016) 694-717.

[5] K. Wang, M.-J. Li, Z.-D. Zhang, C.-H. Min, P. Li, Evaluation of alternative eutectic salt as heat transfer fluid for solar power tower coupling a supercritical CO2 Brayton cycle from the viewpoint of system-level analysis, J. Clean. Prod. 279 (2021) 123472

[6] S. Bazri, I.A. Badruddin, M.S. Naghavi, M. Bahirei, A review of numerical studies on solar collectors integrated with latent heat storage systems employing fins or nanoparticles, Renew. Ener. 118 (2018) 761-778.

[7] O. Achkari, A. El Fadar, Latest developments on TES and CSP technologies - Energy and environmental issues, applications and research trends, Appl. Therm. Eng. 167 (2020) 114806

[8] F.J. Collado, J. Guallar, Quick design of regular heliostat fields for commercial solar tower power plants, Energy 178 (2019) 115-125, https://doi.org/10.1016/j. energy.2019.04.117.

[9] K. Wang, Y.-L. He, Thermodynamic analysis and optimization of a molten salt solar power tower integrated with a recompression supercritical $\mathrm{CO} 2$ Brayton cycle based on integrated modeling, Ener. Conv. Manage. 135 336-350.

[10] M. Schmitz, P. Schwarzbozl, R. Buck, R. Pitz-Paal, Assessment of the potential improvement due to multiple apertures in central receiver systems with secondary concentrators, Sol. Ener. 80 (2006) 111-120, https://doi.org/10.1016/j. solener.2005.02.012.

[11] T. Wendelin, SolTRACE: a new optical modeling tool for concentrating solar optics, Tech. rep., National Renewable Energy Laboratory (NREL) (2003).

[12] M.J. Blanco, J.M. Amieva, A. Mancillas, The Tonatiuh software development project: An open source approach to the simulation of solar concentrating systems, Comput. Inf. Eng. 2005 (2005) 157-164.

[13] D. Jafrancesco, J. Cardoso, A. Mutuberria, E. Leonardi, I. Les, P. Sansoni, F. Francini, D. Fontani, Optical simulation of a central receiver system: Comparison of different software tools, Renew. Sust. Energy Rev. 94 (2018) 792-803.

[14] M. Ebert, D. Benitez, M. Röger, R. Korzynietz, J.A. Brioso, Efficiency determination of tubular solar receivers in central receiver systems, Sol. Ener. 139 (2016) 179-189.

[15] A.L. Ávila Marín, M. Álvarez de Lara, J. Fernández-Reche, Experimental results of gradual porosity volumetric air receivers with wire meshes, Renew. Ener. 122 (2018) 339-353.

[16] J. Kim, J.-S. Kim, W. Stein, Simplified heat loss model for central tower solar receiver, Sol. Energy 116 (2015) 314-322, https://doi.org/10.1016/j. solener.2015.02.022.

[17] P.J. Harper, T.W. von Backström, T.P. Fluri, D.G. Kröger, TRNSYS modeling of a 100 MWe hybrid combined cycle concentrating solar power plant, 2012.

[18] G. Barigozzi, A. Perdichizzi, C. Gritti, I. Guaiatelli, Techno-economic analysis of gas turbine inlet air cooling for combined cycle power plant for different climatic conditions, Appl. Therm. Eng. 82 (2015) 57-67.
[19] F. Petrakopoulou, S. Sánchez-Delgado, C. Marúgan-Cruz, D. Santana, Improving the efficiency of gas turbine systems with volumetric solar receivers, Ener. Conv. Manage. 149 (2017) 579-592.

[20] J. Muñoz-Antón, C. Rubbia, A. Rovira, J.M. Martínez-Val, Performance study of solar power plants with $\mathrm{CO}_{2}$ as working fluid. A promising design window, Energ. Conv. Manage. 92 (2015) 36-46.

[21] R. Korzynietz, J.A. Brioso, A. del Río, M. Quero, M. Gallas, R. Uhlig, M. Ebert, R. Buck, D. Teraji, Solugas - Comprehensive analysis of the solar hybrid Brayton plant, Sol. Ener. 135 (2016) 578-589.

[22] E. Okoroigwe, A. Madhlopa, An integrated combined cycle system driven by a solar tower: a review, Renew. Sust. Energ. Rev. 57 (2016) 337-350.

[23] D. Olivenza-León, A. Medina, A. Calvo Hernández, Thermodynamic modeling of a hybrid solar gas-turbine power plant, Energ. Conv. Manage. 93 (2015) 435-447.

[24] R.P. Merchán, M.J. Santos, I. Reyes-Ramírez, A. Medina, A. Calvo Hernández, Modeling hybrid solar gas-turbine power plants: Thermodynamic projection of annual performance and emissions, Ener. Conv. Manage. 134 (2017) 314-326.

[25] R.P. Merchán, M.J. Santos, I. Heras, J. Gonzalez-Ayala, A. Medina, A. Calvo Hernández, On-design pre-optimization and off-design analysis of hybrid Brayton thermosolar tower power plants for different fluids and plant configurations, Renew. Sust. Energy Rev. 119 (2020) 109590, doi:j.rser.2019.109590.

[26] M.J. Santos, C. Miguel-Barbero, R.P. Merchán, A. Medina, A. Calvo Hernández, Roads to improve the performance of hybrid thermosolar gas turbine power plants: Working fluids and multi-stage configurations, Ener. Conv. Manage. 165 (2018) 578-592.

[27] S. Burgaleta, D.J.I. Ramírez, Gemasolar, the first tower thermosolar commercial plant with molten salt storage, in: Proceedings of SolarPACES, Granada, Spain, 2011.

[28] F.J. Collado, Quick evaluation of the annual heliostat field efficiency, Sol. Ener. 82 (2008) 379-384.

[29] F.J. Collado, J. Guallar, A review of optimized design layouts for solar power tower plants with campo code, Renew. Sust. Energ. Rev. 20 (2013) 142-154.

[30] J. Duffie, W. Beckman, Solar Engineering of Thermal Processes, John Wiley and Sons, Hoboken, New Jersey, 2006.

[31] R.P. Merchán, M.J. Santos, A. Medina, A. Calvo Hernández, Thermodynamic model of a hybrid brayton thermosolar plant, Renew. Ener. 128 (2018) 473-483.

[32] G. Barigozzi, G. Bonetti, G. Franchini, A. Perdichizzi, S. Ravelli, Thermal performance prediction of a solar hybrid gas turbine, Sol. Energy 86 (2012) 2116-2127.

[33] F.J. Collado, Preliminary design of surrounding heliostat fields, Renew. Ener. 34 (2009) 1359-1363.

[34] F.J. Collado, J. Guallar, Campo: Generation of regular heliostat fields, Renew. Ener. 46 (2012) 49-59.

[35] W.B. Stine, M. Geyer, Power from the Sun (2001). http://www.powerfromthesun. net/book.html.

[36] M. Zhang, L. Yang, C. Xu, X. Du, An efficient code to optimize the heliostat field and comparisons between the biomimetic spiral and stagerred layout, Renew. Ener. 87 (2016) 720-730.

[37] C. Noone, M. Torrilhon, A. Mitsos, Heliostat field optimization: a new computationally efficient model and biomimetic layout, Sol. Energ. 86 (2012) $792-803$.

[38] A.W. Dowling, T. Zheng, M. Zavala, Victor, Economic assesssment of concentrated solar power technologies: A review, Renew. Sust. Ener. Rev. 72 (2017) 1019-1032.

[39] J. Hernández-Moro, J.M. Martínez-Duart, Analytical model for solar PV and CSP electricity costs present LCOE values and their future evolution, Renew. Sust. Ener. Rev. 20 (2013) 119-132.

[40] J. Spelling, Hybrid solar gas-turbine power plants, Ph.D. thesis, KTH Royal Institute of Technology, Department of Energy Technology, Stockholm, Sweden (2013).

[41] Solar, Turbines, Caterpillar. [link]. https://mysolar.cat.com/cda/files/126873/7/ dsm50pg.pdf.

[42] M.J. Santos, R.P. Merchán, A. Medina, A. Calvo Hernández, Seasonal thermodynamic prediction of the performance of a hybrid solar gas-turbine power plant, Ener. Conv. Manage. 115 (2016) 89-102.

[43] P.L. Leary, J.D. Hankins, A user's guide for MIRVAL- a computer code for comparing designs of heliostat-receiver optics for cenrtal receiver solar power plants, Tech. rep., Sandia Laboratories (1979).

[44] AEMET, http://www.aemet.es. http://www.aemet.es.

[45] http://www.soda-pro.com/web-services/radiation/cams-radiation-service, Copernicus atmosphere monitoring service (ECMWF) (2019). http://www.sodapro.com/web-services/radiation/cams-radiation-service.

[46] G. Augsburger, Thermo-economic optimisation of large solar tower power plants, Ph.D. thesis (2013)

[47] K. Mohammadi, J.G. McGowan, M. Saghafifar, Thermoeconomic analysis of multistage recuperative Brayton power cycles: Part I- hybridization with a solar power tower system, Ener. Conv. Manage. 185 (2019) 898-919.

[48] Swift, Marshall, Marshall \& Swift Valuation Services. Inventory Index Factors (2018). URL https://www.corelogic.com/products/marshall-swift-valuationservice.aspx.

[49] C. Turchi, G. Heath, Molten salt power tower cost model for the system advisory model (SAM) (2013).

[50] S.A. Wright, C.S. Davidson, W.O. Scamell, Thermo-economic analysis of four sCO2 waste heat recovery power systems, in: 5th Int Symp. Supercrit. CO2 Power Cycle, 2016, pp. 1-16.

[51] S. Trevisan, R.P. Merchán, R. Guedéz, A. Medina, B. Laumert, A. Calvo Hernández, Techno-economic analysis of a solar hybrid combined cycle power plant integrated with a packed bed storage at gas turbine exhaust, in: SolarPACES19, 2019. 
[52] P. Schwarzbözl, R. Buck, C. Sugarmen, A. Ring, M. Marcos Crespo, P. Altwegg, J. Enrile, Solar gas turbine systems: design, cost and perspectives, Sol. Energy 80 (2006) 1231-1240.

[53] C.S. Turchi, Z. Ma, Co-located gas turbine/solar thermal hybrid designs for powe production, Renew, Ener, 64 (2014) 172-179.

[54] G. San Miguel, B. Corona, Economic viability of concentrated solar power under different regulatory frameworks in spain, Renew. Sust. Ener. Rev. 91 (2018) 205-218.

[55] A. Giostri, M. Binotti, C. Sterpos, G. Lozza, Small scale solar tower coupled with micro gas turbine, Renew. Ener. 147 (2020) 570-583.
[56] J. Spelling, B. Laumert, Thermo-economic evaluation of solar thermal and photovoltaic hybridization options for combined-cycle power plants, J. Eng. Gas Turb. Power 137 (2015) 031801-1-031801-11.

[57] A.L. Avila-Marin, J. Fernandez-Reche, F.M. Tellez, Evaluation of the potential of central receiver solar power plants:configuration, optimization and trends, Appl. Ener. 112 (2013) 274-288.

[58] F.J. Collado, J. Guallar, Two-stages optimised design of the collector field of solar power tower plants, Sol. Ener. 135 (2016) 884-896.

[59] SOLGATE. Solar hybrid gas turbine electric power system, Tech. Rep. EUR 21615, European Commission (2005). 